University of Nebraska - Lincoln

DigitalCommons@University of Nebraska - Lincoln

\title{
Long-term analysis of the asynchronicity between temperature and precipitation maxima in the United States Great Plains
}

\author{
Paul Flanagan \\ University of Nebraska-Lincoln, pflanagan@unl.edu \\ Jeffrey B. Basara \\ University of Oklahoma, jbasara@ou.edu \\ Xiangming Xiao \\ University of Oklahoma, xiangming.xiao@ou.edu
}

Follow this and additional works at: https://digitalcommons.unl.edu/natrespapers

Part of the Natural Resources and Conservation Commons, Natural Resources Management and Policy Commons, and the Other Environmental Sciences Commons

Flanagan, Paul; Basara, Jeffrey B.; and Xiao, Xiangming, "Long-term analysis of the asynchronicity between temperature and precipitation maxima in the United States Great Plains" (2017). Papers in Natural Resources. 1110.

https://digitalcommons.unl.edu/natrespapers/1110

This Article is brought to you for free and open access by the Natural Resources, School of at DigitalCommons@University of Nebraska - Lincoln. It has been accepted for inclusion in Papers in Natural Resources by an authorized administrator of DigitalCommons@University of Nebraska - Lincoln. 


\title{
Long-term analysis of the asynchronicity between temperature and precipitation maxima in the United States Great Plains
}

\author{
Paul X. Flanagan, ${ }^{1}$ Jeffrey B. Basara, ${ }^{1,2}$ and Xiangming Xiao ${ }^{3}$ \\ 1 School of Meteorology, University of Oklahoma, Norman, OK \\ 2 Oklahoma Climatological Survey, University of Oklahoma, Norman, OK \\ 3 Department of Microbiology and Plant Biology, Center for Spatial Analysis, \\ University of Oklahoma, Norman, OK \\ Corresponding author - P. X. Flanagan, School of Natural Resources, IANR, \\ University of Nebraska-Lincoln; email pflanagan@unl.edu
}

\begin{abstract}
Agriculture is a critical industry to the economy of the Great Plains (GP) region of North America and sensitive to change in weather and climate. Thus, improved knowledge of meteorological and climatological conditions during the growing season and associated variability across spatial and temporal scales is important. A distinct climate feature in the GP is the asynchronicity (AS) between the timing of temperature and precipitation maxima. This study investigated a long-term observational data set to quantify the AS and to address the impacts of climate variability and change. Global Historical Climate Network Daily (GHCN-Daily) data were utilized for this study; 352 GHCN-Daily stations were identified based on specific criteria and the dates of the precipitation and temperature maxima for each year were identified at daily and weekly intervals. An asynchronous difference index (ADI) was computed by determining the difference between these dates averaged over each decade. Analysis of daily and weekly ADI revealed two physically distinct regimes of ADI (positive and negative), with comparable shifts in the timing of both
\end{abstract}

Published in International Journal of Climatology 37 (2017), pp 3919-3933.

DOI: 10.1002/joc.4966

Copyright (C) 2017 Royal Meteorological Society; published by Wiley. Used by permission. Submitted 27 July 2016; revised 6 October 2016; accepted 21 November 2016; published 24 January 2017. 
the maximum of precipitation and temperature over all six states within the GP examined when comparing the two different regimes. Time series analysis of decadal average ADI yielded moderate shifts ( $\sim 5$ to 10 days from linear regression analysis) in ADI in several states with increased variability occurring over much of the study region.

Keywords: climate, climatology, precipitation, temperature, Great Plains

\section{Introduction}

The growing season (GS), which spans from March to October in the northern hemisphere during which plants and crops emerge after the cold season and grow until leaf fall (Linderholm, 2006), is typically associated with increased temperature, and precipitation as well as increased variability in ground and surface moisture fluxes [e.g. evapotranspiration (ET) and soil moisture (Durre et al., 2000; Illston et al., 2004; Teuling and Troch, 2005)]. Recent climate change research has focused on the effects of global climate change on regional precipitation (e.g. Ruiz-Barradas and Nigam, 2010; Bukovsky and Karoly, 2011; Groisman et al., 2012; Long et al., 2012; Christian et al., 2015; Shi and Durran, 2016), temperature (e.g. Kunkel et al., 2010; Long et al., 2012; Kumar et al., 2013; Berg et al., 2015) and plant health and phenology (e.g. Tubiello et al., 2002; Weltzin and McPherson, 2003; Bertin, 2008; Schlenker and Roberts, 2009; Jamieson et al., 2012; Zeppel et al., 2014). However, while impacts of climate change on vegetation health have been studied, most have focused on specific plant and crop impacts (Olesen and Bindi, 2002; Tubiello et al., 2007; Schlenker and Roberts, 2009; Jongen et al., 2011) rather than regional GS climate.

Because small changes to temperature and precipitation trends incur significant impacts on vegetation during the GS, such impacts are extremely important to examine (Lobell and Asner, 2003). The temperature magnitude, timing of temperature increases/decreases and overall maximum are important to crop phenology (e.g. Hughes, 2000; Menzel, 2003; Badeck et al., 2004; Menzel et al., 2006; Cleland et al., 2007; Bertin, 2008) and can impact plant growth and maturity (Menzel, 2003). Thus, as temperature warms more quickly vegetation will mature earlier in the GS and shift the timing at which water stress will be higher due to quicker plant mass growth (Martyniak, 2008) as the temperature magnitude and temperature maxima determine the timing of peak ET and thus the timing of peak water usage (Bartz and 
Brecht, 2002; Vivoni et al., 2008; Blum, 2010). If water availability is not sufficient for the vegetation, plant health can be adversely affected (Turner and Begg, 1981; Blum, 2010).At the same time, Schlenker and Roberts (2009) noted that the negative effects of extreme temperatures on corn crops during June and July could be mitigated by increases in precipitation. Thus the seasonality and variability of precipitation also yield significant impacts to vegetation health in concert with temperature.

Beyond the basic requirement of sufficient water for vegetation sustenance, the timing of precipitation can also impact plant health and crop production. Fay (2009) demonstrated that variations in precipitation impacted food resource availability while also finding that microbial processes are sensitive to soil moisture that can impact the availability of nitrogen in the soil. This leads to a sensitivity of nitrogen availability to trends in soil moisture and as the timing between rainfall events increases the availability of nitrogen decreases. Di et al. (1994) modelled the relationship between normalized difference vegetation index (NDVI) and precipitation and suggested that the response to NDVI from precipitation events changes throughout the GS and found that plants more effectively utilized water from precipitation events during the earlier and later portions of their growing cycle, but less so when the plant was more mature. Furthermore, Di et al. (1994) noted that due to plant root depth and size, deeper soil moisture was more important later in the GS than earlier. Thus, precipitation events are more important earlier in the season to maintain overall soil moisture storage essential to vegetation (Vivoni et al., 2008; Méndez-Barroso et al., 2009).

Unlike most grasslands and croplands around the world, the maxima in temperature and precipitation during the Great Plains (GP) of North America GS do not occur at the same time whereby the maxima in precipitation precedes the climatological maxima in temperature. Because the agricultural industry in the GP is of critical socioeconomic importance (Fischer et al., 2007), the impacts of climate change on the seasonality of precipitation and temperature, especially during the GS, are critically important. At the same time, numerous studies have noted changes in the timing of precipitation and temperature across interior portions of North America (e.g. Stewart et al., 2004; Regonda et al., 2005; Caesar et al., 2006; Schwartz et al., 2006). However, the asynchronicity (AS) between the timing of precipitation and 
temperature maxima have not been examined and yet are critical to GS processes in the region. Thus, the purpose of this study was to examine the climatological AS between the timing of precipitation and temperature maxima in the GP using historical observations to determine whether long-term changes in AS have occurred.

\section{Data and methods}

\subsection{Global historical climatology network-daily data}

To investigate the long-term trends in the AS of temperature and precipitation maxima, a climate data set of surface observations was required. The Global Historical Climatology Network's Daily (GHCNDaily) data set (Menne et al., 2012) was utilized for this study. A network of sensors that spans the globe and has been in operation for over 100 years, the data set provides daily maximum temperature and precipitation observations from over 80 ooo weather stations. Only stations contained within the GP of the United States (Figure 1) were retained for this study which spanned from 1895 to 2015. Furthermore, similar to Christian et al. (2015), the GP was defined to include the states of Texas, Oklahoma, Kansas, Nebraska, South Dakota

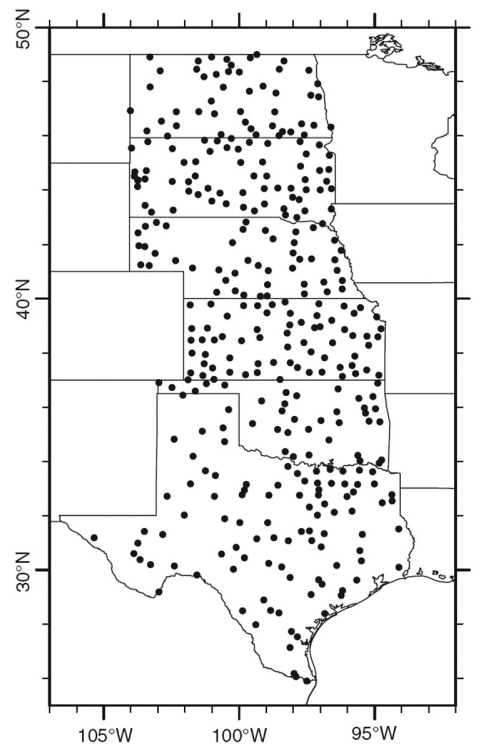

Figure 1. Map of the Great Plains showing the location of each GHCN-Daily station used in this study. 
and North Dakota. A length of period (>90 years) requirement was used to filter out stations with short periods of record. However, no filter was used to remove stations without continuous data sets during this period as few stations within the data set have a continuous, long-term record of observations. Thus, earlier decades may not contain observations from all stations shown in Figure 1. After filtering was completed, a total of 352 stations were identified within the GP region. As seen in Figure 1, the distribution of stations covers the entire region, with few noticeable gaps. To focus only on the spring precipitation maximum and the summer temperature maximum consistent with the GS, the period was constrained from March through August of each year.

While the GHCN-Daily data set is useful for climate studies due to its long period of record, biases exist in the daily data that can mask or artificially induce trends within the data set (Karl et al., 1988). Additionally, the GHCN data set is hindered by: time of observation bias (Karl et al., 1986), instrumentation bias (Quayle et al., 1991), station location change bias (Karl and Williams, 1987) and a bias caused by urbanization near or at the station site (Karl et al., 1988). While bias correction algorithms exist for monthly averaged data a comparable method of removing these biases from the daily data sets does not exist. However, histogram analysis on the date of maximum temperature (Figure 2) and precipitation (Figure 3) from the GHCN-Daily data set shows that dates from each state match the climatological date of the respective maxima (Figure 4 ).

\subsection{Asynchronous difference index}

To quantify the climatological difference between the maxima of temperature and precipitation, an index was created. The asynchronous difference index (ADI) computes the difference between the dates of the two maxima which allows for a simplistic quantitative analysis of the data set. For this study, the ADI was defined as the difference between the date of maximum temperature and the date of maximum precipitation, as shown in Equation (1):

$$
\mathrm{ADI}=\operatorname{Dmax}_{\text {temp }}-\operatorname{Dmax}_{\mathrm{prec}}
$$



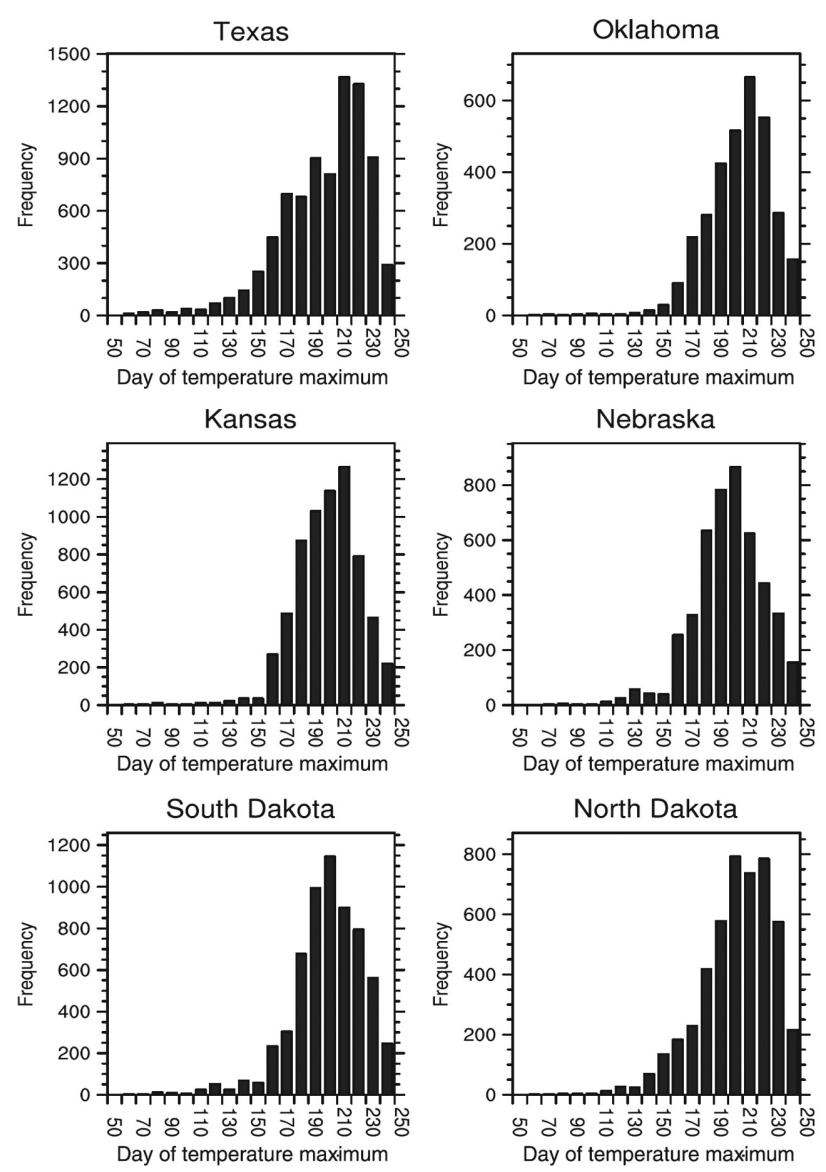

Figure 2. Histogram of dates for maximum temperature throughout the entire GHCN-Daily data set for each state.

where ADI $=$ asynchronous difference index, $D \max _{\text {Temp }}=$ date (day or week) of highest maximum temperature and $D \max _{\text {Prec }}=$ date (day or week) of maximum precipitation amount.

This formulation was developed to obtain a positive average ADI during climatological conditions. As can be seen in Figures 2 and 3, the dates of maximum precipitation and temperature cannot be approximated as normal distributions. However, the ADI normalizes these two data sets and allows for a more simplistic statistical methodology to be utilized for analysis.

To deduce the effect of different methodologies in finding the 'date' of maxima, two separate techniques of analyzing the data for the maximum date were utilized. First, the day of maximum temperature and precipitation was analyzed from the 352 stations for each year. The ADI was then developed from this data set of daily maximum 

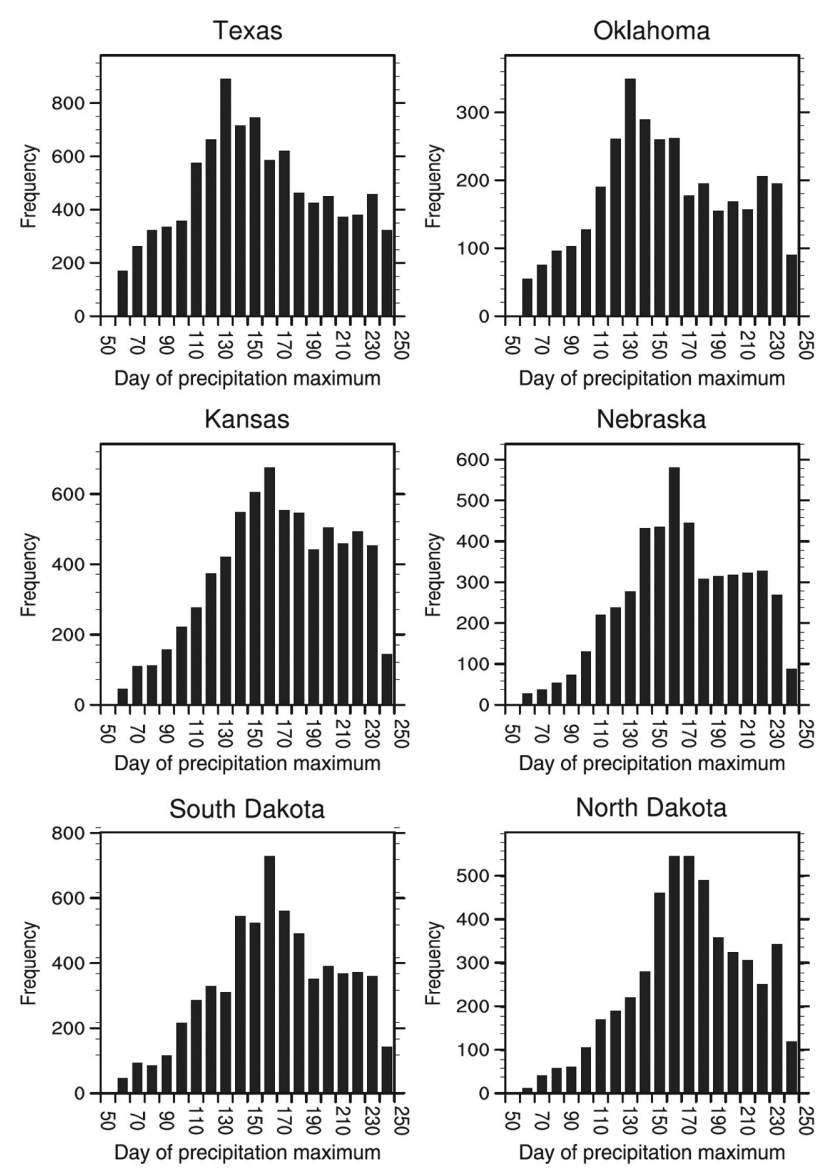

Figure 3. Same as Figure 2, except for precipitation.

temperature and precipitation for each year (daily ADI). Second, daily observations were averaged, or for precipitation the sum total was determined, for each week and then the maximum week within the period yielded the date Figure 3. Same as Figure 2, except for precipitation. of maximum. Weeks were designated as 1 through 26 for our period, with the first week starting on the third day of March for each year. This was done to exclude data from September in the last week of each period and constrain the data set to the same period as the other two date methodologies. The ADI was then computed as the difference between the 2-week numbers and then multiplied by seven to obtain an approximation for the number of days (weekly ADI). This was done so that a direct comparison between the daily and weekly results could be completed. Statistical analysis was then completed for each version of the ADI including the mean, standard deviation, 

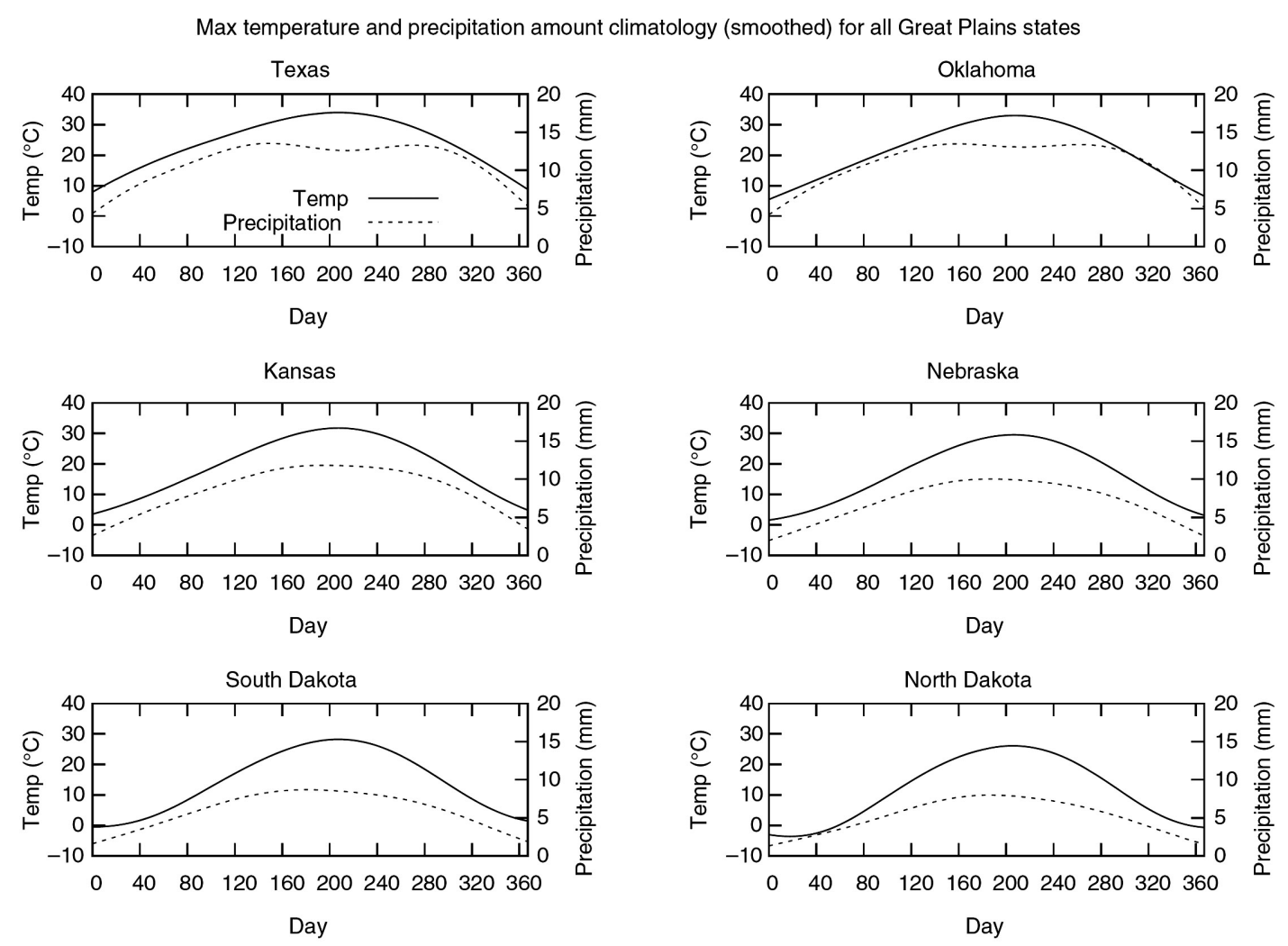

Figure 4. Temperature and precipitation climatology from the GHCN-Daily data set. Dashed line is precipitation $(\mathrm{mm})$ and the solid line is temperature $\left({ }^{\circ} \mathrm{C}\right)$. Lines were smoothed due to the variability in the daily precipitation climatology.

Student's $t$-test significance tests and linear regression. Student's $t$ tests were completed on the decadal ADI data set using the 1890-1949 period as an estimate for the population statistic and the 1950-2015 period as the test statistic. The latter was assigned due to recent results noted by Christian et al. (2015) and Weaver et al. (2016), which found increasing variability of precipitation across the GP after 1950.

\section{GP' temperature and precipitation climatology}

Using the GHCN-Daily data set, a climatology of precipitation and maximum temperature was created for each state within the study domain (Figure 4). This daily climatology was then smoothed (using a kernel density estimate for a random collection of points) to remove the influences of fluctuations on the precipitation climatology. All six states have similar temperature climatology with a maximum 
in mid-summary (late July, day 200), but differ in precipitation climatology. The four northern states have a peak of precipitation during early summer (June, day 160), but the southern states have a bimodal pattern of precipitation with one peak during spring (May, $\sim$ day 140) and another peak during fall (October, day 280). In this article, the analyses focus on the study period from March to August, which includes both the climatological temperature maximum and the first (spring) climatological precipitation maximum. Ending the study period at August removes the unwanted secondary precipitation maximum evident in the Texas and Oklahoma precipitation climatology that occurs in September/October and beyond the critical GS.

\section{Results}

\subsection{Spatial ADI analysis}

Climatologically, ADI yielded features that are commonly seen within the GP climate (Figure 5). A strong gradient of ADI was analyzed over the Southern Great Plains (SGP), especially in Texas and

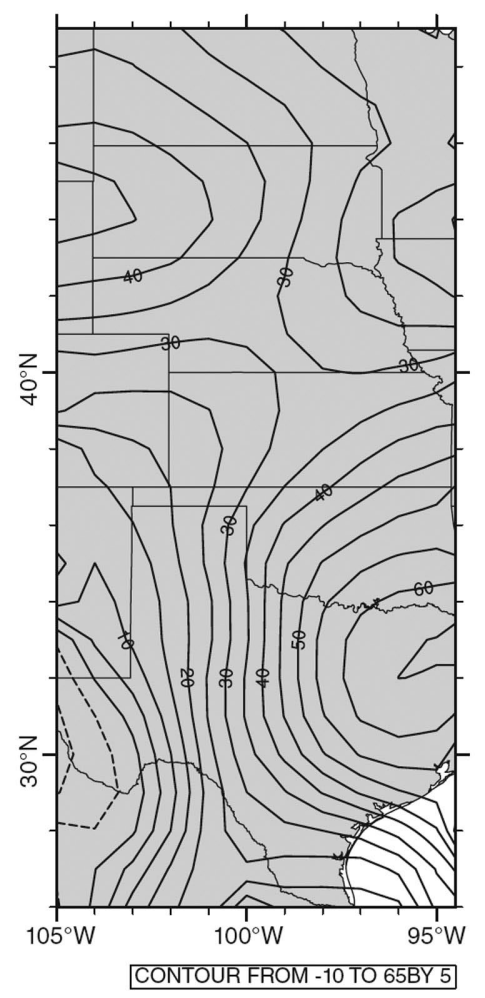

Figure 5. Mean ADI for the entire study period (1890-2015) from the GHCN dataset. Solid lines are for positive ADI and dashed lines represent negative ADI. Data was gridded using the Barnes objective analysis methodology in order to display smoother contours compared to contouring raw ADI at the station level. 
Oklahoma. This matches well with the known gradient of precipitation that occurs within this region of the GP. Further to the north, a reversal of this gradient occurs and ADI was climatologically lower in the eastern portion of the Northern Great Plains (NGP) when compared to the western portions of this portion of the GP. The SGP ADI pattern is likely due to the overall east to west gradient of precipitation whereby climatologically more rainfall falls in the eastern portion of the SGP. This would cause temperatures to reach their yearly maximum at a later date due to increased latent heat flux. Across the western portion of the SGP, less precipitation occurs and temperature values increase more rapidly and earlier in the year. In the NGP domain, this pattern is more difficult to describe as the east to west gradient of rainfall still occurs in this portion of the GP as well and ADI appears to be controlled more so by the date of maximum rainfall than temperature (Figure 6). A gradient in the date of maximum rainfall occurred across the NGP (decreasing to the west) without a corresponding gradient in the date of maximum temperature and would yield higher ADI
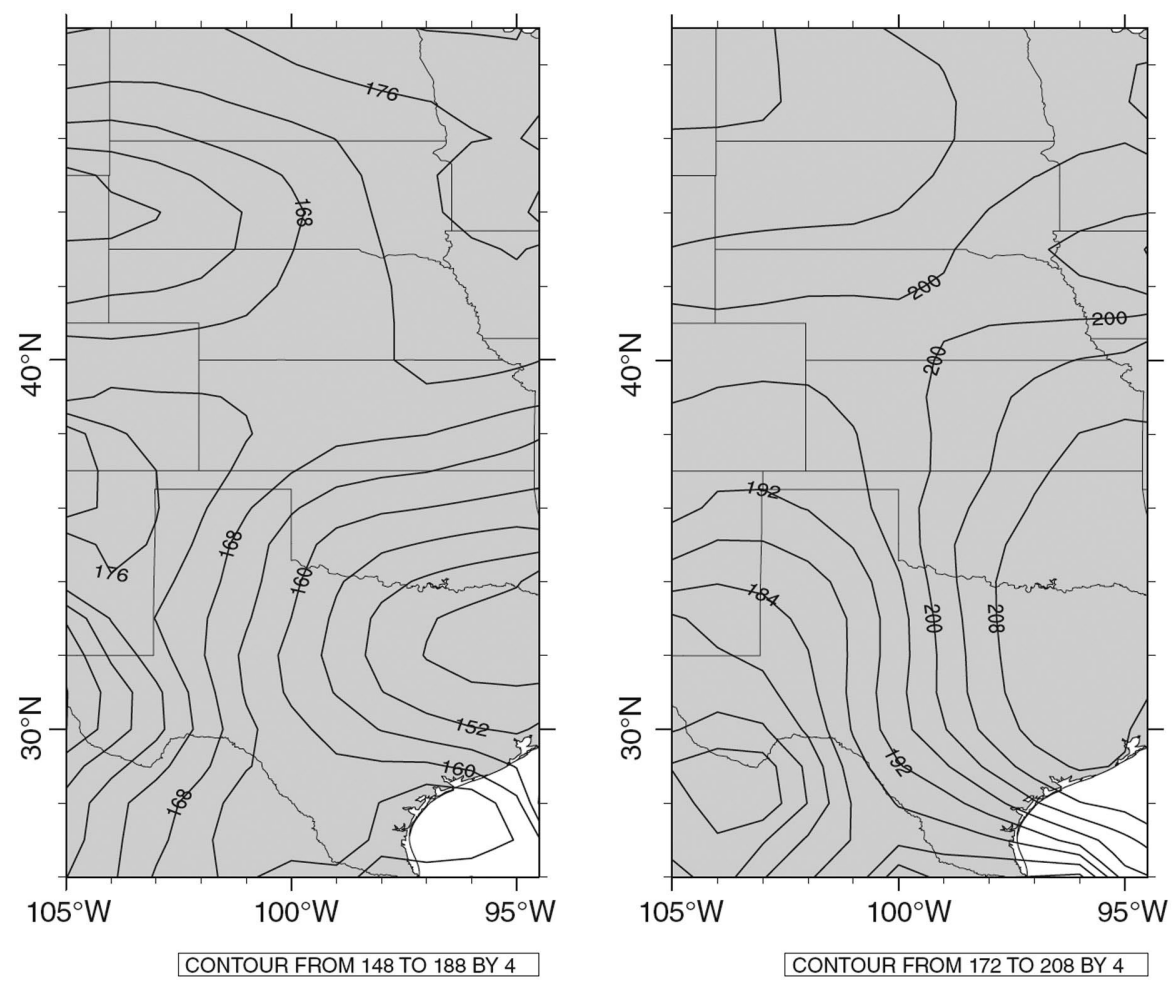

Figure 6. Same as Figure 5, except for the date of maximum precipitation (a) and temperature (b). 
in the western portion of the NGP as seen in the mean ADI analysis (Figure 5). The cause of the later date of maximum precipitation in the NGP compared to the SGP is due to mesoscale convective system (MCS) activity that occurs in the early summer within the GP, which has been noted numerous times in previous studies (e.g. Rasmusson, 1971; Wallace, 1975; Easterling and Robinson, 1985).

Spatial analysis of ADI standard deviation shows significant variability in the ADI (40-50 days), with (slightly) larger values $(\sim 50+$ ) in the SGP compared to the NGP ( $\sim 48$; Figure 7$)$. This is expected, as the SGP has been noted to have higher precipitation variability when compared to the NGP (Figure 8; Weaver et al., 2016). The spatial pattern of variability in the date of maximum precipitation (Figure 8(a)) depicts a pattern much like that of the overall ADI variability. These results demonstrate that the variability in the ADI is most likely due to the variability in the date of maximum precipitation more so than the date of the temperature maxima. This result mirrors what is seen in mean $\mathrm{ADI}$, as the date of maximum precipitation appeared to have more control on the climatological mean of ADI than the date of maximum daily temperature.

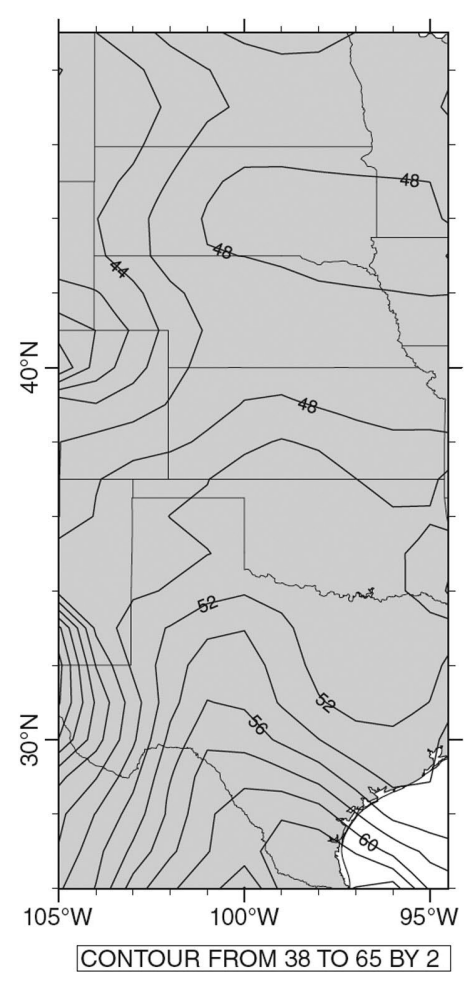

Figure 7. ADI standard deviation for the entire study period (1890-2015) from the GHCN data set. Data was gridded using the Barnes objective analysis methodology in order to display smoother contours compared to contouring raw ADI at the station level. 

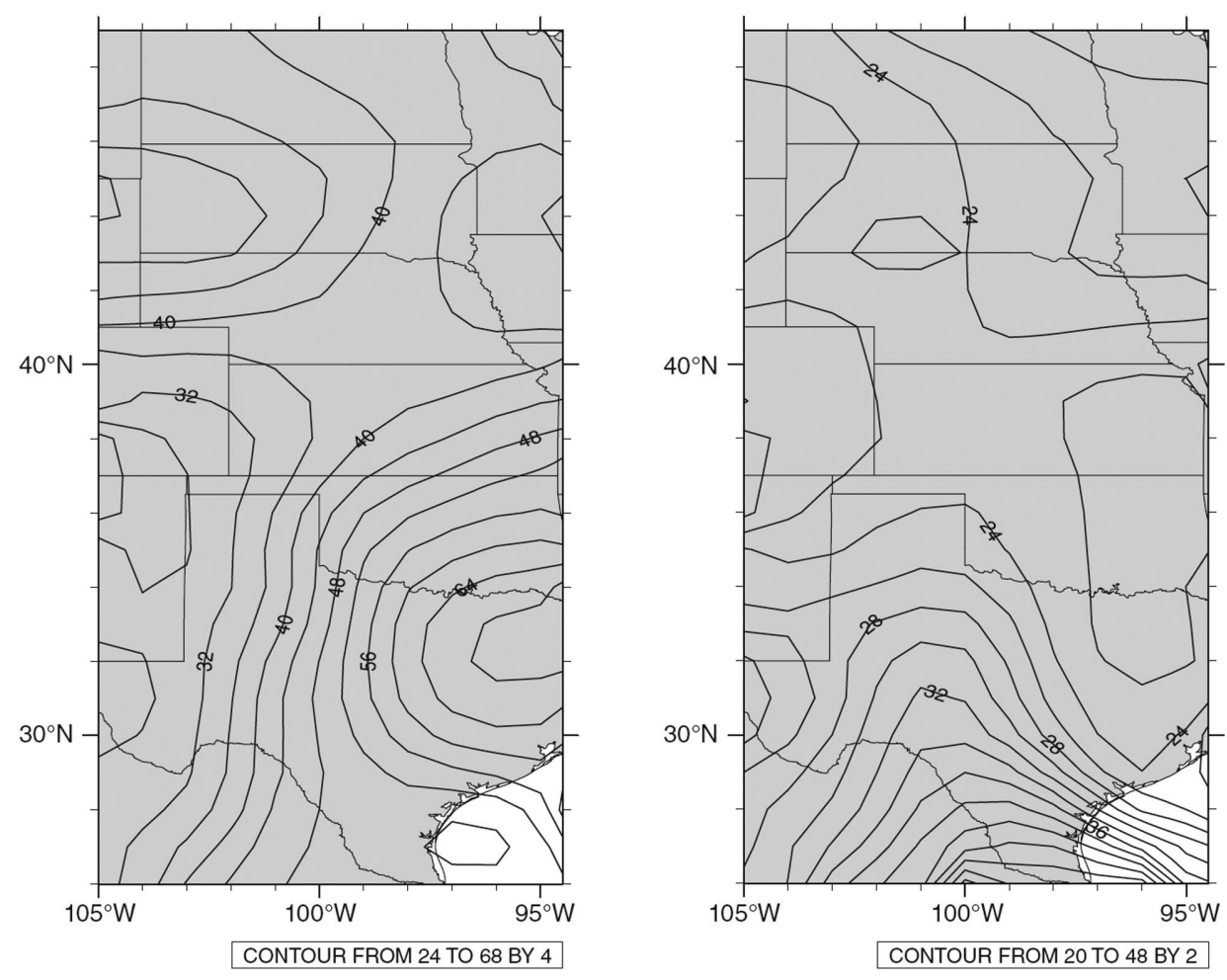

Figure 8. Same as Figure 7, except for date of maximum precipitation (a) and temperature (b).

\subsection{Temporal ADI analysis}

Histograms of all daily (Figure 9) and weekly (Figure 10) ADI values showed a normal distribution around a positive value of ADI. This was expected as climatologically within the period from March to August the temperature maximum occurs later than the precipitation maximum. Furthermore, within the GP climate, it is difficult to get a precipitation and temperature maximum to occur on the same day, and few zero values of ADI were expected. However, a secondary peak in the negative range of ADI was not expected. To examine whether the valley in the zero values caused this to peak to exist as a function of the ADI itself (i.e. not a physical, real phenomenon) analysis of the average day/week of maximum temperature and precipitation was completed for each state (Table 1). Results demonstrated that the average date of maximum precipitation changed from approximately late May (positive ADI) to late July (negative ADI), an expected result 

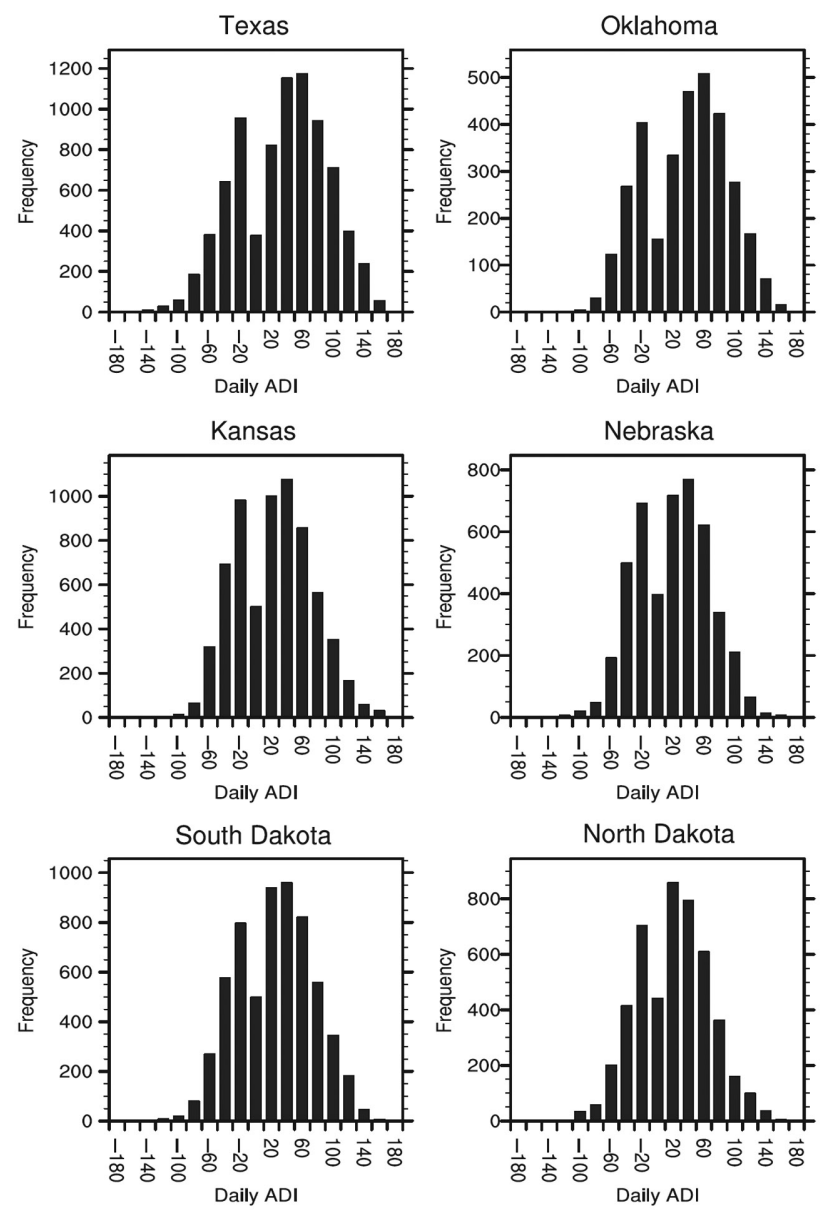

Figure 9. Histogram of daily ADI values throughout the study period for each state.

given the MCS activity that occurs later in the warm season. However, the change of the average date of temperature maximum from late July (positive ADI) to late June (negative ADI) was not. Summertime temperature maxima over the GP are climatologically caused by a strong mid-tropospheric ridge that develops over the region during the summer (Illston et al., 2004). Thus, a shift in the maximum temperature as systematic as shown via the negative ADI analysis does not have a simple explanation.

To determine the cause of this shift in maximum temperature within the two different ADI regimes, several features that influence surface temperatures over the GP were investigated. First, the influence of precipitation on ADI was investigated due to links between latent/sensible heat flux and surface moisture heterogeneities caused 

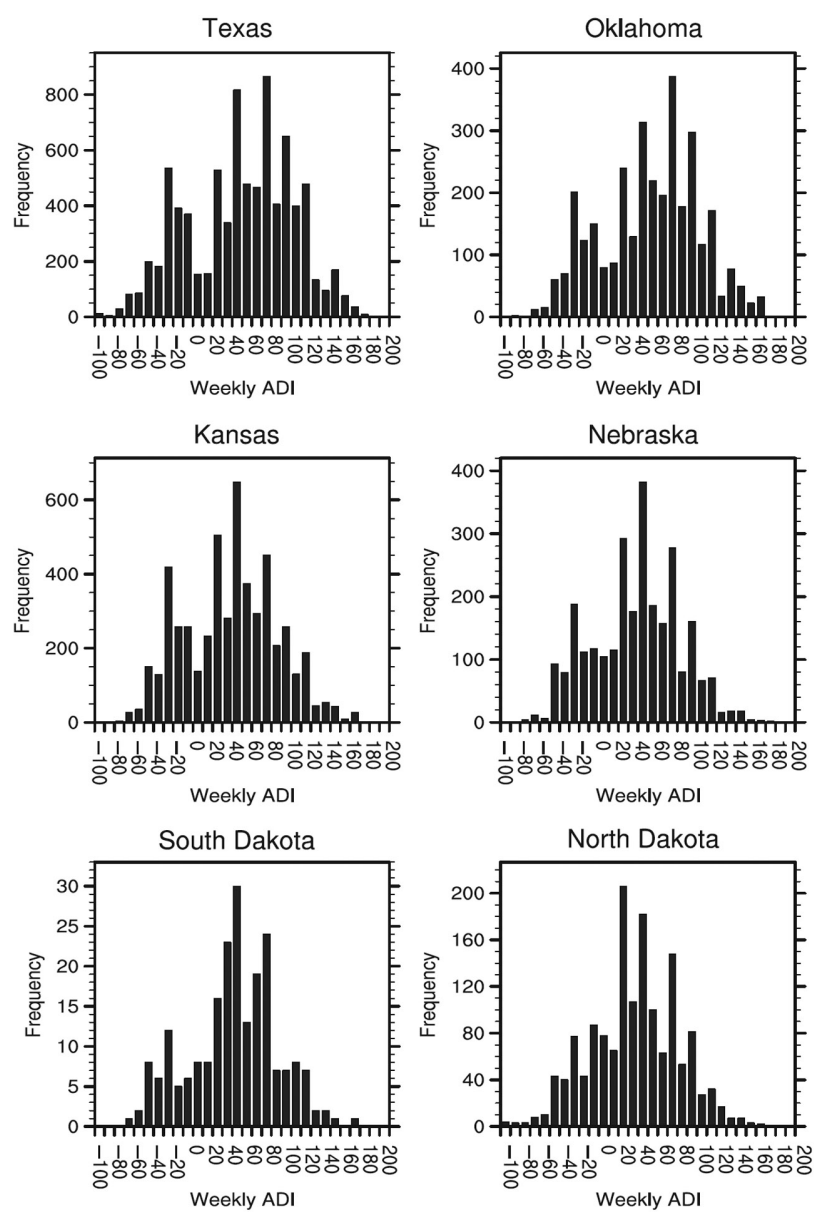

Figure 10. Same as Figure 9, except for weekly ADI.

by precipitation (e.g. Seneviratne et al., 2010; Berg et al., 2014). Results from this analysis showed no significant correlations between $\mathrm{ADI}$ and any of the precipitation totals computed from the station data. Next, correlations between noted teleconnection patterns that influence North American temperature patterns (Ropelewski and Halpert, 1986) and the ADI were analyzed. For this study, the Pacific-North American (PNA) pattern, El Niño Southern Oscillation (ENSO), North American Oscillation (NAO), Pacific Decadal Oscillation (PDO) and the Atlantic Multidecadal Oscillation (AMO) were chosen. Using monthly ADI values derived from the monthly climate division GHCN data set (nClimDiv) to compute correlations with these teleconnection patters, results from this analysis again showed little to no correlations between any of the teleconnection patterns and the ADI. Lastly, the role of the climatological $500 \mathrm{mb}$ ridge that develops during the summer 
Table 1. Average date of temperature and precipitation maxima separated by state and for negative/positive ADI. The number of observations and the percent of total are also shown.

\begin{tabular}{|c|c|c|c|c|c|}
\hline \multicolumn{6}{|l|}{ Daily } \\
\hline \multirow[t]{2}{*}{ Texas } & Negative ADI & 177.66 & 209.03 & 2261 & 27.80 \\
\hline & Positive ADI & 209.1 & 136.82 & 5872 & 72.20 \\
\hline \multirow[t]{2}{*}{ Oklahoma } & Negative ADI & 192.16 & 216.8 & 831 & $25 \cdot 57$ \\
\hline & Positive ADI & 211.91 & 140.66 & 2419 & 74.43 \\
\hline \multirow[t]{2}{*}{ Kansas } & Negative ADI & 189.6 & 214.83 & 2080 & 31.12 \\
\hline & Positive ADI & 208.5 & 149.6 & 4604 & 68.88 \\
\hline \multirow[t]{2}{*}{ Nebraska } & Negative ADI & 184.84 & 210.54 & 1460 & 31.71 \\
\hline & Positive ADI & 206.62 & 152.09 & 3144 & 68.29 \\
\hline \multirow[t]{2}{*}{ South Dakota } & Negative ADI & 186.09 & 212.34 & 1753 & 28.70 \\
\hline & Positive ADI & $209 \cdot 52$ & 150.67 & 4354 & 71.30 \\
\hline \multirow[t]{2}{*}{ North Dakota } & Negative ADI & 186.03 & 211.53 & 1420 & 29.65 \\
\hline & Positive ADI & 212.96 & 159.23 & 3369 & 70.35 \\
\hline \multicolumn{6}{|l|}{ Weekly } \\
\hline \multicolumn{2}{|c|}{ GHCN-Daily data } & Temp. & Prec. & No. of obs. & $\%$ of total \\
\hline \multirow[t]{2}{*}{ Texas } & Negative ADI & 18.76 & 22.54 & 1888 & 23.18 \\
\hline & Positive ADI & 21.92 & 11.62 & 6257 & 76.82 \\
\hline \multirow[t]{2}{*}{ Oklahoma } & Negative ADI & $19 \cdot 51$ & 22.8 & 634 & 19.44 \\
\hline & Positive ADI & 21.91 & 11.86 & 2627 & 80.56 \\
\hline \multirow[t]{2}{*}{ Kansas } & Negative ADI & 19.22 & 22.67 & 1711 & 25.60 \\
\hline & Positive ADI & 21.61 & 13.17 & 4973 & 74.40 \\
\hline \multirow[t]{2}{*}{ Nebraska } & Negative ADI & 18.85 & 22.31 & 1005 & 21.83 \\
\hline & Positive ADI & 21.42 & 13.42 & 3599 & 78.17 \\
\hline \multirow[t]{2}{*}{ South Dakota } & Negative ADI & 18.71 & 22.39 & 1183 & 19.25 \\
\hline & Positive ADI & 21.64 & 13.13 & 4963 & 80.75 \\
\hline \multirow[t]{2}{*}{ North Dakota } & Negative ADI & 18.19 & 22.14 & 1093 & 22.75 \\
\hline & Positive ADI & 21.74 & 14.28 & 3711 & 77.25 \\
\hline
\end{tabular}

The bolded information is the average day (for daily method) or week (for weekly method) of the maximum of temp/prec. This was used to show the difference between the average date of each for negative ADI and positive ADI observations.

season (Bluestein, 1993; Illston et al., 2004) over the GP was investigated. Using NOAA-CIRES 2oth Century Reanalysis Version 2 (Compo et al., 2011), monthly average $500 \mathrm{mb}$ geopotential heights were correlated with gridded yearly ADI [gridded using an iterative improvement type objective analysis scheme within the NCAR Command Language (NCL)]. Results from this analysis showed more utility in describing the causes of the differences between the positive and negative ADI regimes (correlations of $\sim 0.3$ with July $500 \mathrm{mb}$ heights), however, no significant correlations were found during this analysis. Thus, no direct causation of the negative and positive ADI regimes could be found 
Mean Decadal Async Difference Index (ADI; Daily ADI) for all Great Plains States

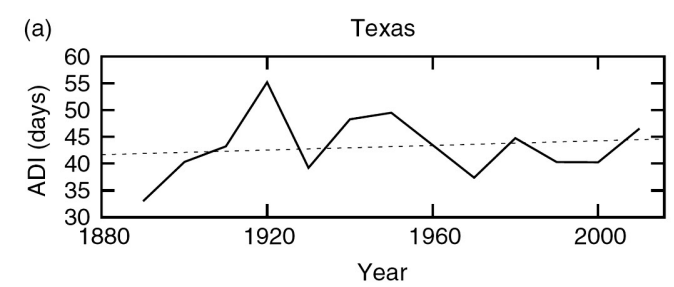

Texas: $t$-test statistic $-0.008, P$-value 0.497

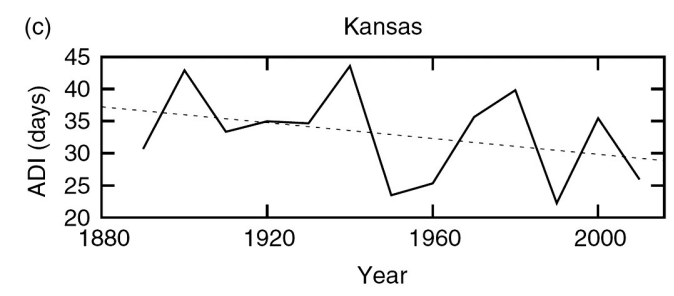

Kansas: $t$-test statistic $-3.230, P$-value 0.012

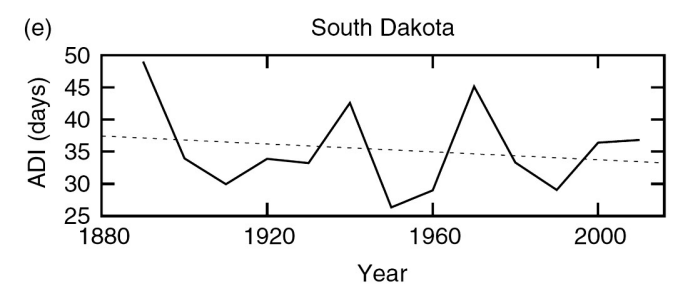

South Dakota: $t$-test statistic $-1.150, P$-value 0.151

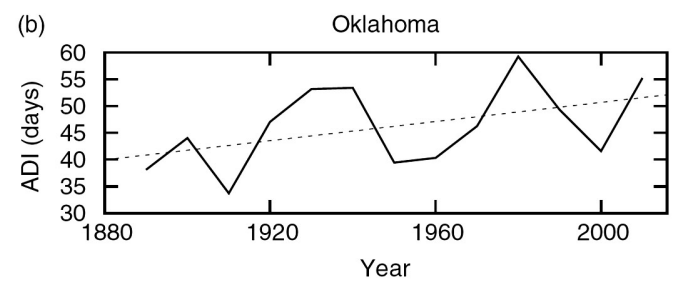

Oklahoma: $t$-test statistic $0.748, P$-value 0.244

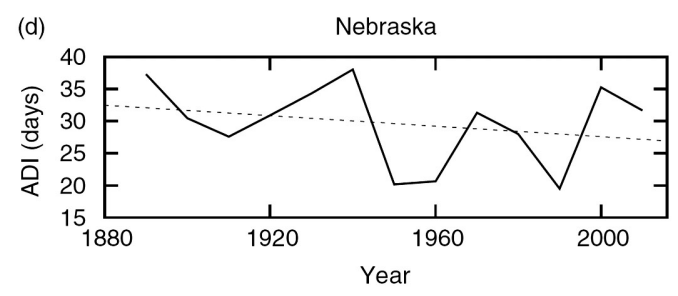

Nebraska: $t$-test statistic $-3.820, P$-value 0.006

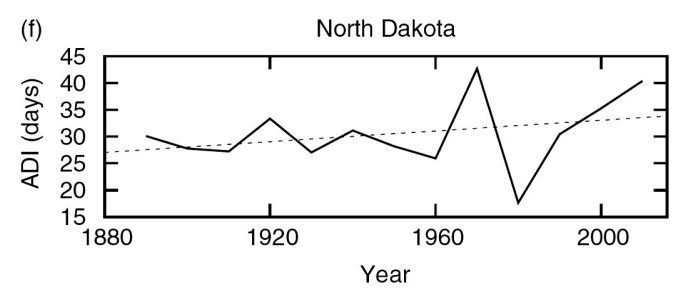

North Dakota: $t$-test statistic 1.999, $P$-value 0.051

Figure 11. Decadal average daily ADI for each state in the study domain. Solid line shows the decadal average, while the dashed line is the linear regression line created from the ADI data. (a) Texas, (b) Oklahoma, (c) Kansas, (d) Nebraska, (e) South Dakota and (f) North Dakota.

from the analysis performed within this study. Further investigation into this feature of the ADI is warranted given the physical difference between the two regimes and the impacts they impart on the ecosystems of the GP.

\subsection{Daily $A D I$}

Statewide decadal mean values of daily ADI (Figure 11) reveal a number of results across the GP. Mean ADI values were positive and show a systematic difference ( $\sim 30$ to 45 days) between temperature and precipitation maxima throughout the historical record. Texas and Oklahoma had larger mean ADI values, which were expected as they 
showed the earliest precipitation peak of the GP states. The other four states were considerably lower, with no mean ADI value analyzed above 50 compared to 60 for Texas and Oklahoma. However, this difference appears to be changing with time over the length of the observational record. Linear trend analysis shows that each state is incurring a trend on its decadal mean ADI. For example, Texas, Oklahoma and North Dakota are incurring positive trends. However, using 18901949 data as the population statistic for the $t$-test, only North Dakota is showing a statistically significant difference (90\% confidence level). Conversely, Kansas, Nebraska and South Dakota yielded negative trends in ADI with Kansas and Nebraska showing a statistically significant difference (95\% confidence level) using 1890-1949 as the population statistic for the $t$-test. Thus, from the daily ADI analysis a significant shift in ADI was analyzed in Kansas, Nebraska and North Dakota using a Student's $t$-test for significance between the 1890-1949 and 1950-2015 periods. This was confirmed with the linear regression lines for each of the three states. The results for Oklahoma displayed a linear regression line with a strong ( $\sim 14$ days) positive trend, however, the $t$-test did not show that the two periods were significantly different. This is likely due to the pattern of high and low mean ADI values that are seen throughout the time series, which would overwhelm the comparatively smaller signal of the overall increase for this statistical test.

Daily ADI variability analysis (Figure 12) also showed significant differences between the two periods. The average standard deviation of daily ADI across the region ranged from $\sim 40$ to 55 days, with the southern portion of the domain having higher variability than the northern states. Linear increases were noted in Texas, South Dakota and North Dakota that were statistically significant (95\% confidence level) with the other three states also having slight (<4 days) positive standard deviation trends. It is evident in analysis of the ADI standard deviation time series that after the 1940 decadal period an increasing trend can be seen in many states (Texas, Oklahoma, Nebraska, and North Dakota) even though a strong overall trend was not determined through the linear regression analysis. Thus, the analysis shows that ADI variability is increasing over the GP, with significant increases in three of the states at the $95 \%$ confidence level. 
Decadal ADI Standard Deviation (Daily ADI) for all Great Plains States

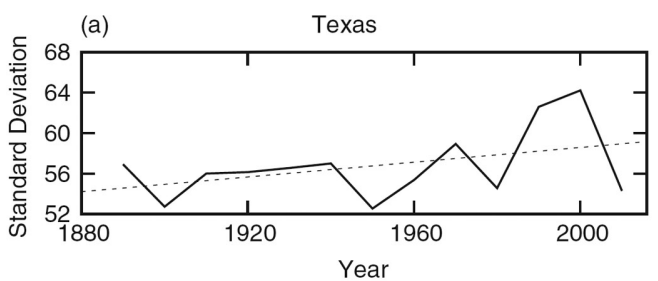

Texas: $t$-test statistic 2.463, $P$-value 0.029

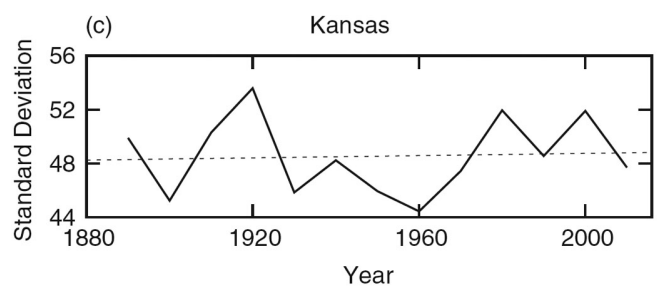

Kansas: $t$-test statistic $-0.454, P$-value 0.334

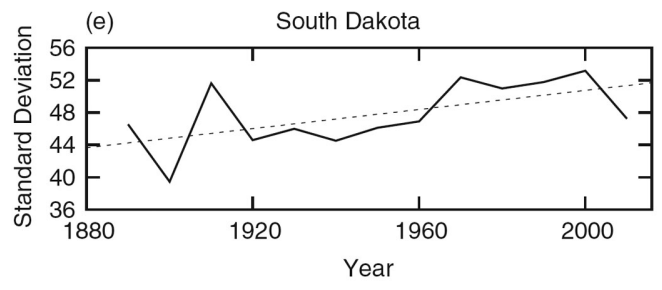

South Dakota: $t$-test statistic $2.700, P$-value 0.021

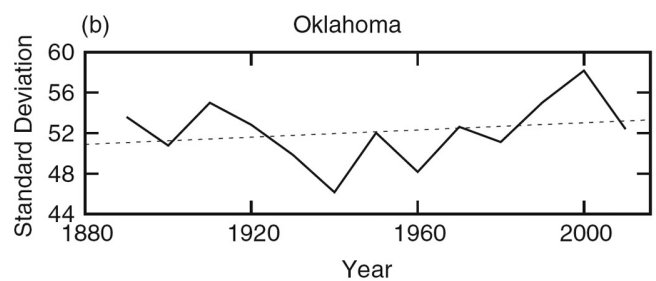

Oklahoma: $t$-test statistic $1.104, P$-value 0.160

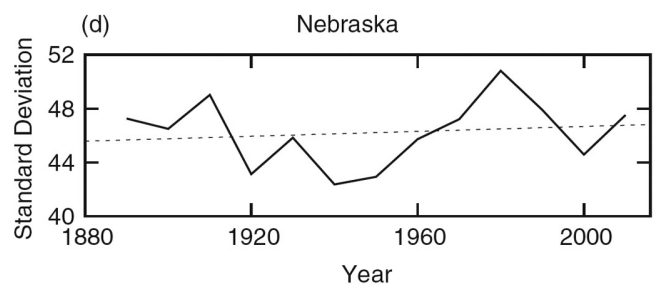

Nebraska: $t$-test statistic $0.954, P$-value 0.192

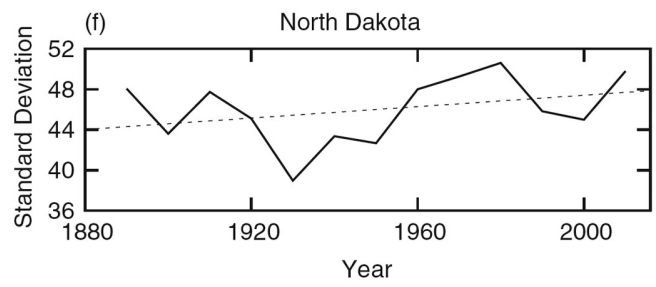

North Dakota: $t$-test statistic 2.069, $P$-value 0.047

Figure 12. Same as Figure 11, except for daily ADI standard deviation.

\subsection{Weekly ADI}

Analysis of the weekly ADI statewide decadal means (Figure 13) showed similar results as daily ADI. Weekly ADI continues to show systematic positive ADI of $\sim 30$ to 45 days throughout the data set record. This shows that the methodology does not affect the overall results of obtaining a climatologically positive ADI, but the actual value of ADI in the weekly ADI analysis is higher when compared to daily ADI for the same state. Thus, the change of methodology did not change the overall nature of ADI, but it did change the decadal mean magnitudes, which affected the linear trends. Near zero trends in Texas, Nebraska and South Dakota were seen with stronger trends in Oklahoma, Kansas and North Dakota. The negative trend in Kansas was slightly higher in the weekly ADI results ( $~ 8$-day increase) compared to the daily ADI ( $\sim 7$-day increase), with the trend in North Dakota showing 
Mean Decadal Async Difference Index (ADI; Weekly ADI) for all Great Plains States
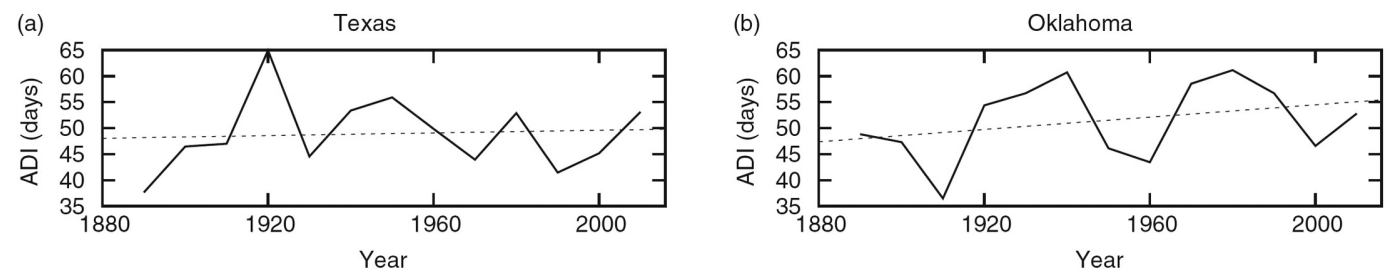

Texas: $t$-test statistic $-0.024, P$-value 0.491

Oklahoma: $t$-test statistic $0.415, P$-value 0.348
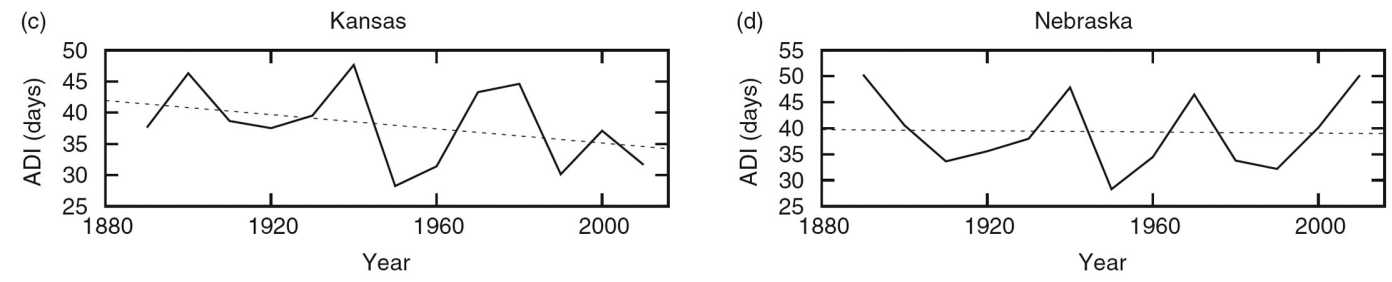

Nebraska: $t$-test statistic $-1.109, P$-value 0.159

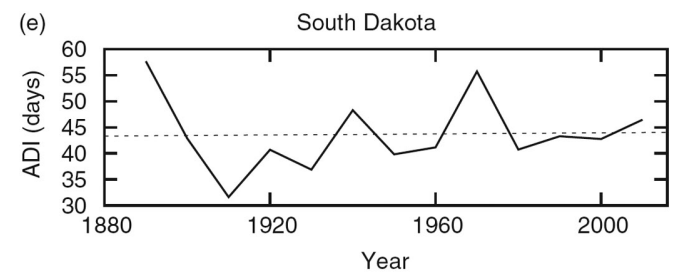

South Dakota: $t$-test statistic $0.342, P$-value 0.373

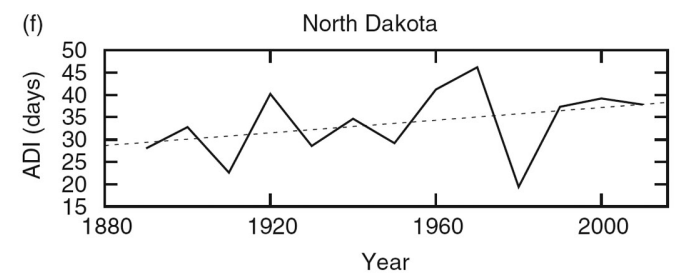

North Dakota: $t$-test statistic $1.845, P$-value 0.062

Figure 13. Same as Figure 11 except for weekly ADI decadal averages.

a similar change (weekly ADI $~ 10$-day increase, daily ADI $\sim 7$-day increase). The trend in Oklahoma, however, showed a slightly weaker increase in the weekly ADI ( $~ 8$-day increase) compared to the daily ADI ( 13-day increase). At the same time, the statistical significance did change. Kansas and North Dakota still revealed significant differences between the two subset periods, however, Nebraska no longer showed statistically significant results. This implies that the methodology (daily ADI) likely resulted in the statistical significance for $\mathrm{Ne}$ braska rather than the results shown in the daily ADI analysis being a physically meaningful result.

Variability in the weekly ADI (Figure 14) showed similar features to the daily ADI as well, however, with a decreased magnitude owing to the averaging of the daily data. The average value of variability in the region was $\sim 40$ to 50 days, with a majority of the values in the 40 os. Furthermore, the trends align with the daily ADI variability, with Nebraska being the main difference. In the daily ADI analysis, Nebraska 
Decadal ADI Standard Deviation (Weekly ADI) for all Great Plains States

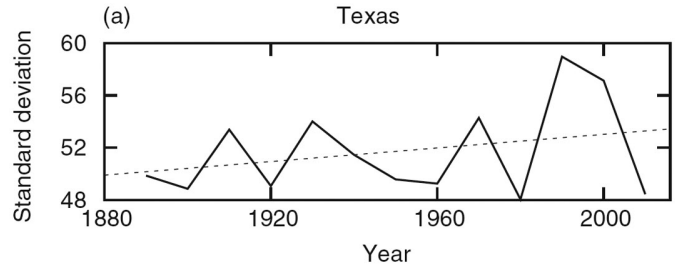

Texas: $t$-test statistic $1.258, P$-value 0.132

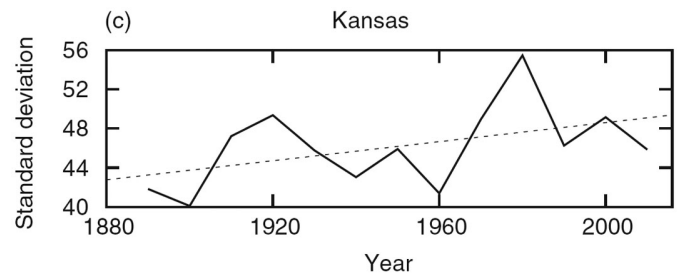

Kansas: $t$-test statistic $1.187, P$-value 0.144

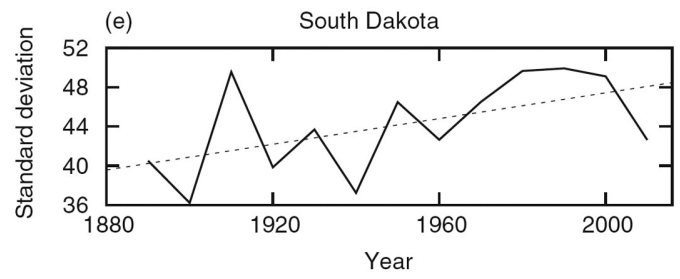

South Dakota: $t$-test statistic 2.781, $P$-value 0.019

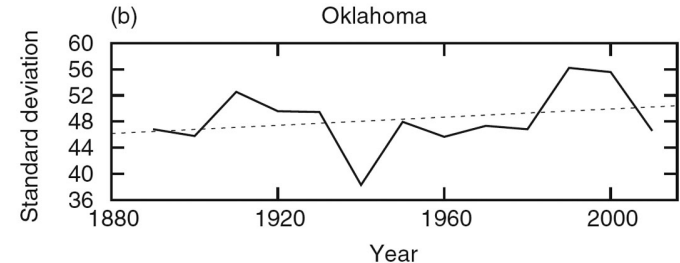

Oklahoma: $t$-test statistic $1.180, P$-value 0.145

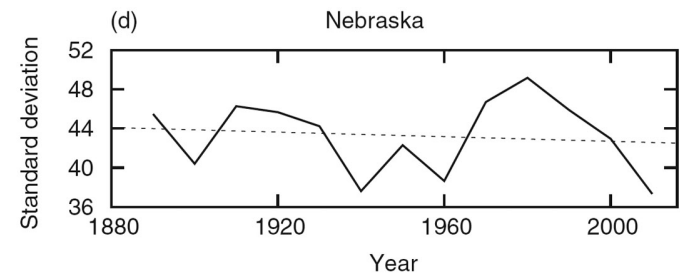

Nebraska: $t$-test statistic $0.003, P$-value 0.499

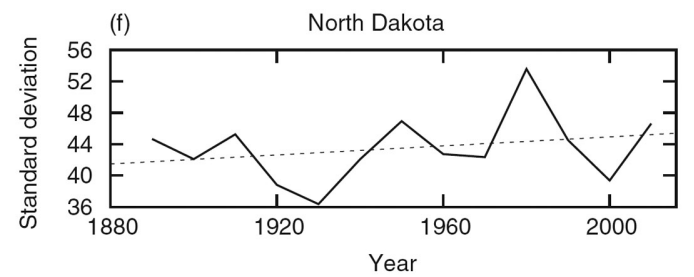

North Dakota: $t$-test statistic 2.595, $P$-value 0.024

Figure 14. Same as Figure 11, except for weekly ADI standard deviation.

yielded a non-statistically significant increase in variability. However, with the weekly ADI analysis, it showed a decreasing trend in variability, showing that no trend in ADI variability is occurring within Nebraska. Furthermore, the five other states show very similar signals as the daily ADI analysis whereby increasing trends were observed in all five states, with South and North Dakota being statistically significant at the 95\% level (note - Texas, Oklahoma and Kansas were statistically significant at the $85 \%$ confidence level). The difference in these five states is Kansas, which analyzed the weekly ADI analysis to have a much stronger ( $\sim 7$ days) increasing trend compared to the daily ADI ( 1-day increase) variability analysis. The other four states have close to the same trend in variability (approximately same number of day increases), compared to the daily ADI analysis, from 1890 to 2015 analyzed through a linear regression analysis. 


\section{Discussion and conclusions}

The goal of this study was to analyse the long-term trends in the AS between the date of maximum temperature and precipitation (Figure 4) across the GP. To accomplish this task, long-term data gathered from the GHCN-Daily database for maximum temperature and precipitation was utilized and an ADI was developed by computing the day of each relevant maxima and further computing the temporal span between the date of maximum temperature and precipitation. This was also completed for the week of maximum by averaging the data into weekly values and determining the week of each maximum before computing the difference between the weeks of each maximum. These ADI values were then averaged into decadal means, and multiple statistical analyses were utilized in the analysis.

Overall, the results show that ADI is changing throughout the 18902015 period for various states in the GP. Daily (Figure 11) and weekly (Figure 13) ADI analyses yielded a statistically significant decreasing trend in Kansas (95\% confidence level for both analyses) with a statistically significant increase in North Dakota (90\% confidence level for both analyses). Trends in other states show significance for one analysis or the other, with Nebraska showing a significant decrease (95\% confidence level) in the daily ADI analysis, but not the weekly analysis. Linear regression analysis on the Oklahoma data shows a strong increasing trend in both ADI analyses, however, significance testing on the difference between the 1890-1949 and 1950-2015 periods shows no statistically significant difference. This is likely because of the variable pattern exhibited within both the daily and weekly ADI decadal means, which caused the overall mean of both decades (the test statistics for the Student's $t$-test) to be similar even though an overall increasing trend is seen.

Analysis of ADI standard deviation shows an increasing trend (linear regression lines) for both analyses and most states (Figures 12 and 14). The only state to not show an increasing linear trend was Nebraska for the weekly ADI analysis, which resulted in a slight decreasing trend. Statistical significance (95\% confidence level) was seen in both analyses for South and North Dakota, with the daily ADI analysis showing a significant increase in variability for Texas (95\% confidence level). Although statistical significance may not have been noted, a 
Average Julian Day of Maximum (Daily ADI) for all Great Plains States Temperature

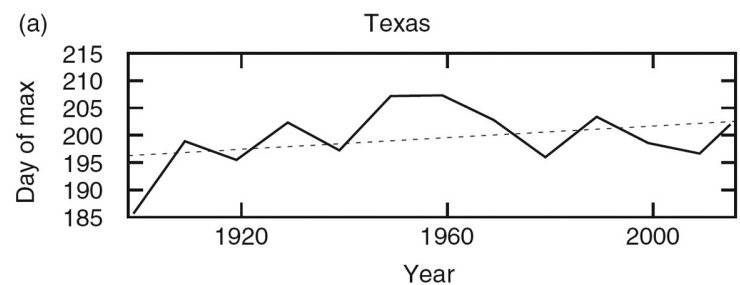

Texas Temp: $t$-test statistic 1.069, $P$-value 0.167

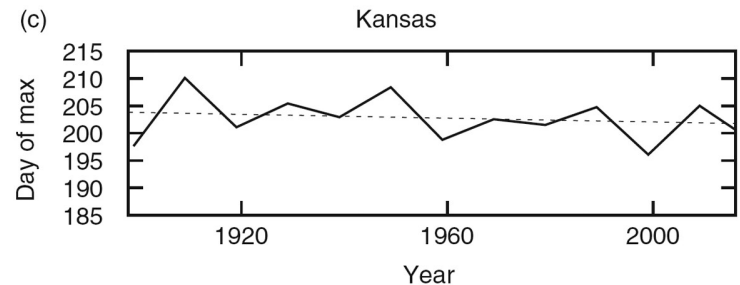

Kansas Temp: T-Test Statistic $-1.690, P$-value 0.076

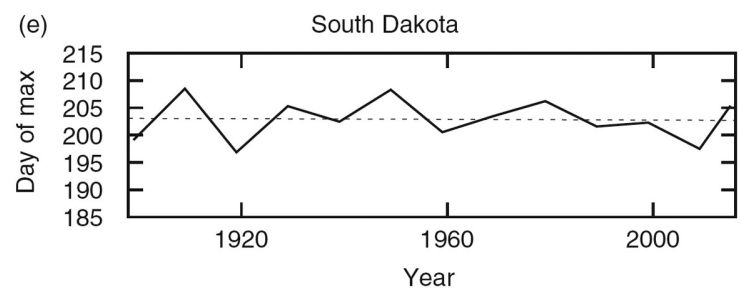

South Dakota Temp: $t$-test statistic $-0.511, P$-value 0.316

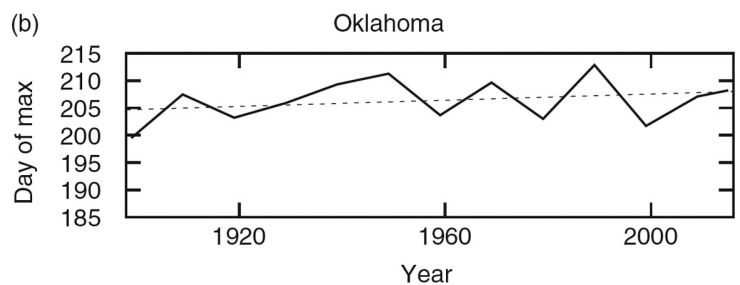

Oklahoma Temp: $t$-test statistic $0.282, P$-value 0.395

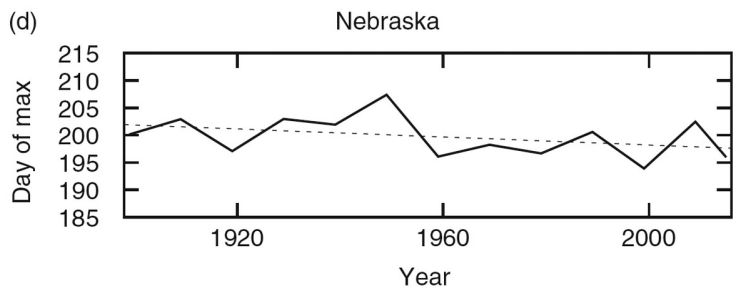

Nebraska Temp: $t$-test statistic $-3.116, P$-value 0.013

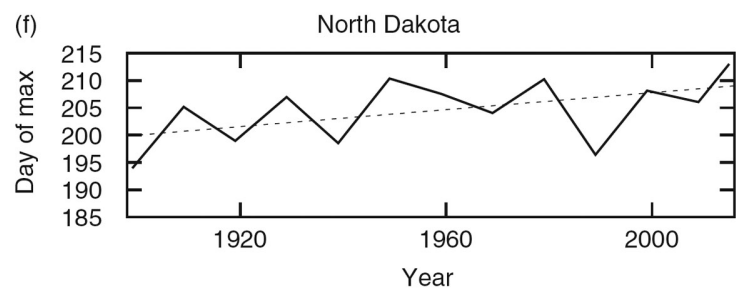

North Dakota Temp: $t$-test statistic 1.657, P-value 0.079

Figure 15. Decadal average date of maximum temperature for daily ADI method. Solid line is the decadal average and the dashed line is a linear regression line created from the decadal average data.

difference was seen between the prior to 1950 and after 1950 decadal variability for several states. It appears as though a relative minimum in ADI variability occurred in the 1940 and then it increased from the 1950s onward in the central and SGP states (Texas, Oklahoma, Kansas and Nebraska). This result was observed in both ADI analyses.

Determining the drivers of the trends seen in ADI is difficult as the timing of maxima during a particular season is rarely studied. However, an analysis into which variable (temperature or precipitation) is driving the changes in ADI can be completed within the purview of this study. Daily analysis showing the decadal average day of maximum temperature (Figure 15) and precipitation (Figure 16) for Oklahoma, Kansas, Nebraska and North Dakota (states with notable linear trends or significant differences between periods) demonstrated 
Average Julian Day of Maximum (Daily ADI) for all Great Plains States Precipitation

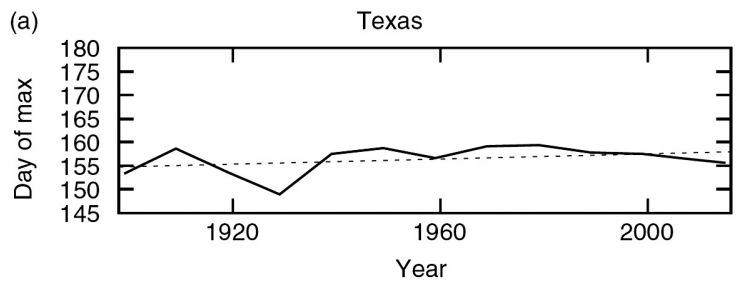

Texas Prec: $t$-test statistic 1.482, $P$-value 0.099

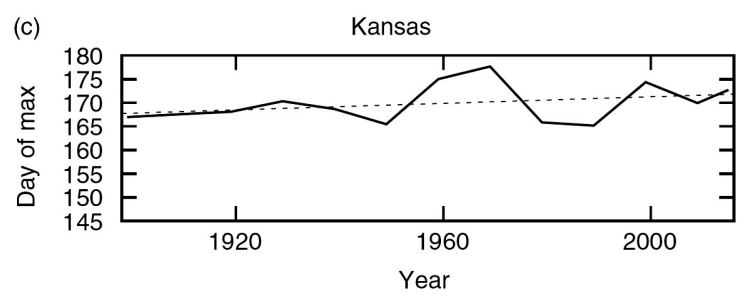

Kansas Prec: $t$-test statistic 5.526, $P$-value 0.001

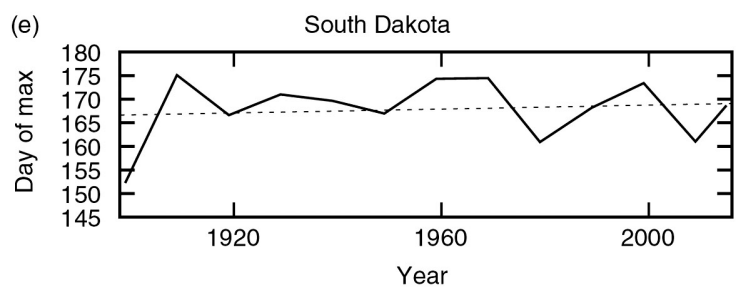

South Dakota Prec: $t$-test statistic $0.556, P$-value 0.301

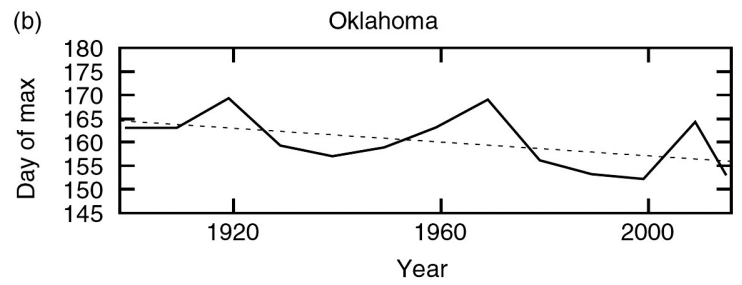

Oklahoma Prec: $t$-test statistic -1.691, $P$-value 0.076

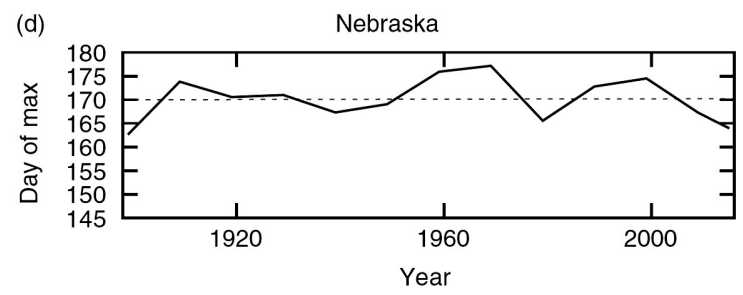

Nebraska Prec: $t$-test statistic 1.249, $P$-value 0.133

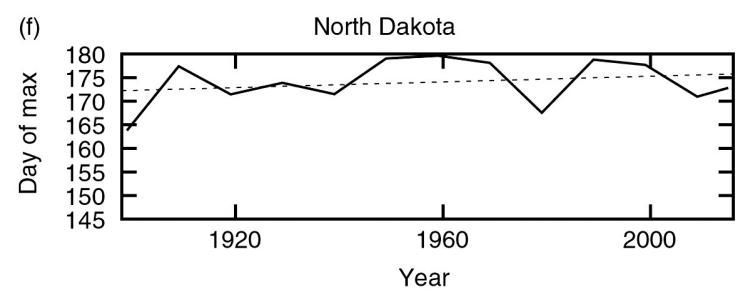

North Dakota Prec: $t$-test statistic 1.016, $P$-value 0.178

Figure 16. Same as Figure 15 except for precipitation.

that changes in the date of maximum temperature are the likely cause of the shift in ADI for North Dakota and Nebraska while a shift in the date of maximum precipitation being the cause for Oklahoma. The Kansas analysis displayed statistically significant differences (90\% confidence level or above) for both the date of maximum temperature and precipitation. Weekly analysis of decadal average day of maximum temperature (Figure 17) and precipitation (Figure 18) demonstrated that only the trend in ADI for Oklahoma can be partially attributed to shifts in the date of maximum precipitation (90\% confidence level) with Kansas and Oklahoma both yielding significant shifts (95\% confidence level) in their date of maximum temperature. Because all of these shifts in the date of maximum temperature and precipitation impact the decadal mean ADI, a positive shift in ADI represents either a positive shift in temperature, a negative shift in precipitation 
Average Week of Maximum (Weekly ADI) for all Great Plains States Temperature

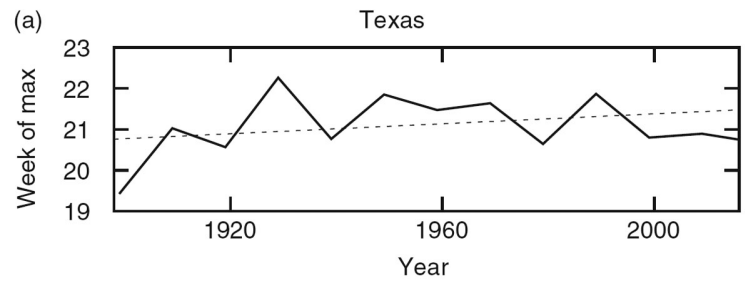

Texas Temp: $t$-test statistic $0.393, P$-value 0.355

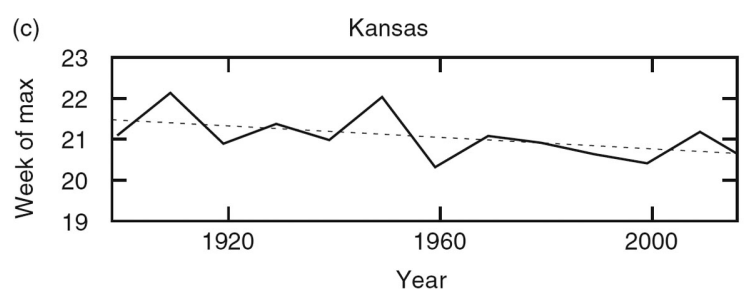

Kansas Temp: $t$-test statistic $-3.209, P$-value 0.012

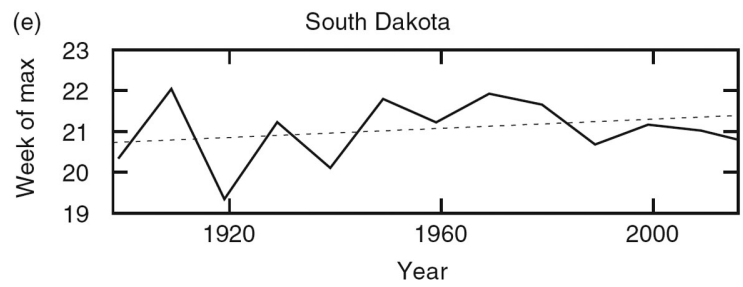

South Dakota Temp: $t$-test statistic $0.900, P$-value 0.205

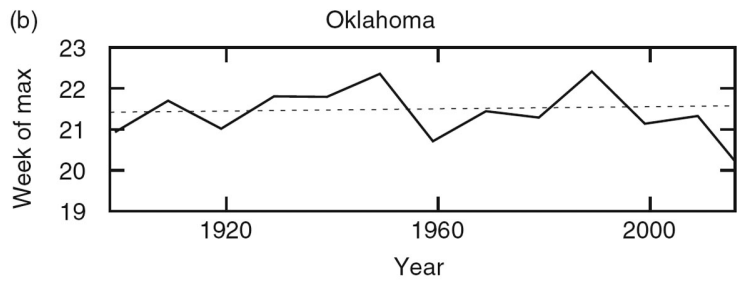

Oklahoma Temp: $t$-test statistic $-2.029, P$-value 0.049

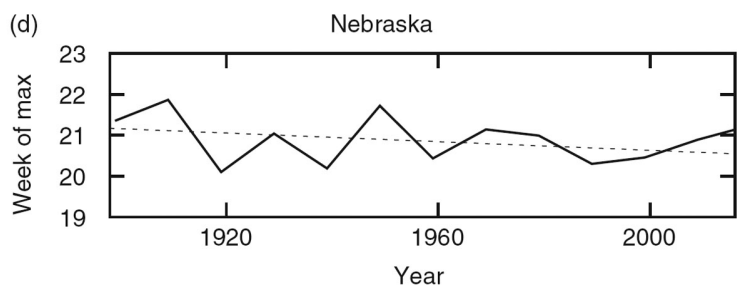

Nebraska Temp: $t$-test statistic $-0.866, P$-value 0.213

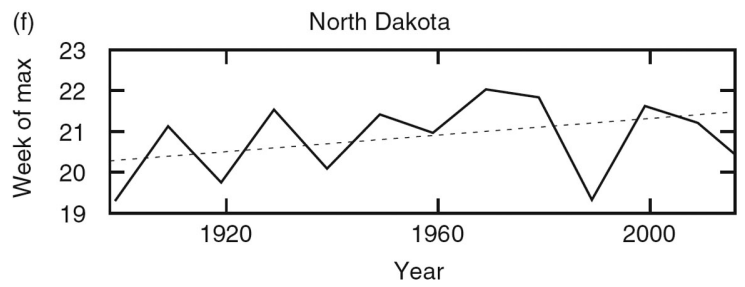

North Dakota Temp: $t$-test statistic $1.241, P$-value 0.135

Figure 17. Same as Figure 15, except for weekly ADI method.

or both. Conversely, a negative shift in ADI reflects either a positive shift in precipitation, a negative shift in temperature or both. Overall, the shifts in the date of the occurrence of March to August maximum temperature show more significance in regards to the overall shifts in the ADI for both methodologies. However, it is important to note that using the Student's $t$-test for this data may introduce errors, but because simple bootstrap significant tests showed similar results as those detailed above, the same methodology was used for all analyses in the study.

The impact of the shifts between temperature and precipitation maxima is critical to the climate of the GP region. Changes to the GS of the region impact ecosystem health, water resources and socioeconomic viability and sustainability. For example, small shifts in the timing of maximum temperature (e.g. Hughes, 2000; Menzel, 2003; Badeck et al., 2004; Menzel et al., 2006; Cleland et al., 2007; Bertin, 
Average Week of Maximum (Weekly ADI) for all Great Plains States Precipitation

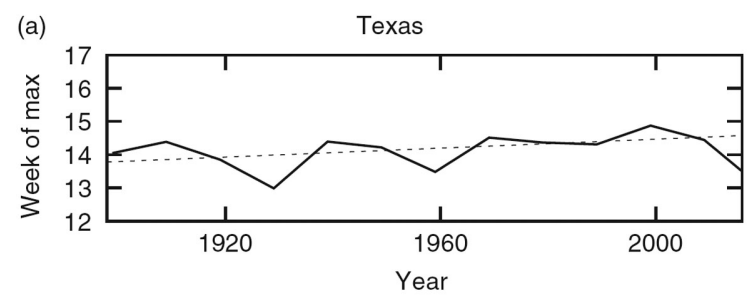

Texas Prec: $t$-test Statistic 0.803, $P$-value 0.229

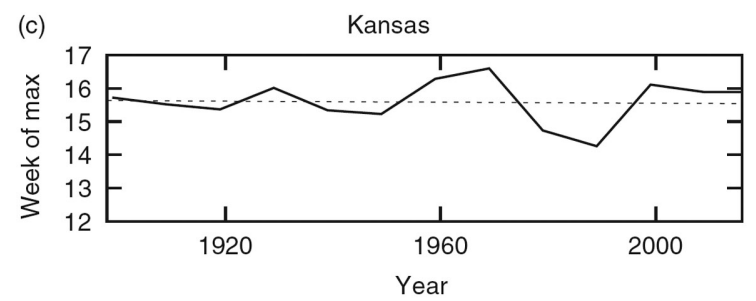

Kansas Prec: $t$-test Statistic 1.251, $P$-value 0.133

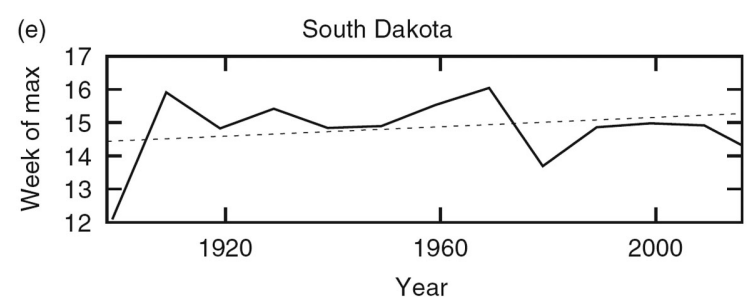

South Dakota Prec: $t$-test Statistic $0.376, P$-value 0.361

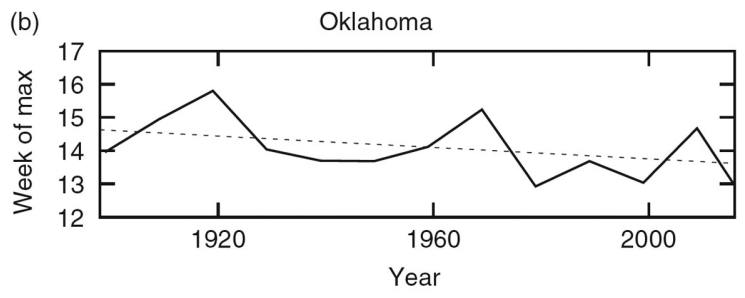

Oklahoma Prec: $t$-test Statistic $-1.893, P$-value 0.058

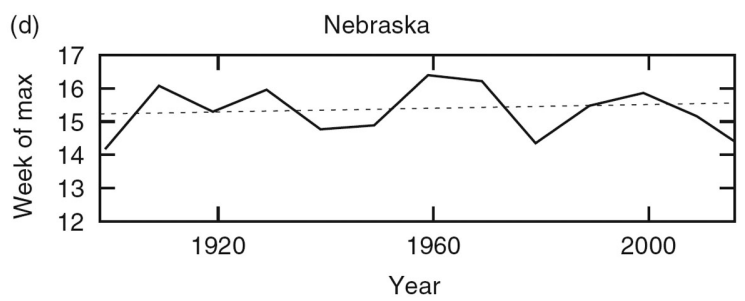

Nebraska Prec: $t$-test Statistic $0.560, P$-value 0.300

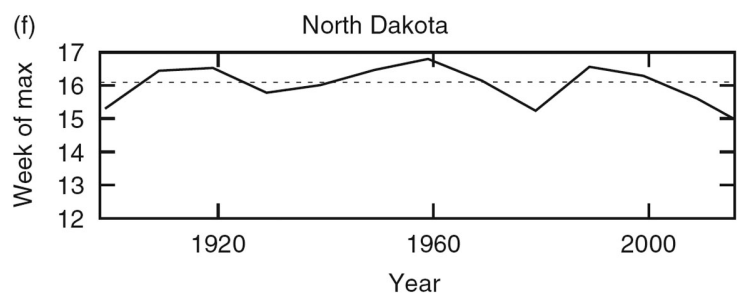

North Dakota Prec: $t$-test Statistic $-0.911, P$-value 0.202

Figure 18. Same as Figure 15, except for weekly ADI method precipitation.

2008) and precipitation (Di et al., 1994; Vivoni et al., 2008; Fay, 2009; Méndez-Barroso et al., 2009) incur significant changes to plant and crop phenology. This results in changes in water resource management (i.e. irrigation, land management, etc.) along with the timing of seeding and harvesting (Terjung et al., 1984; Rosenzweig, 1990) to maintain the current ecosystem and level of agricultural production. However, not all shifts in ADI could impact the ecosystem negatively. Lower values of ADI could indicate higher soil moisture values during the peak time of water stress, or when temperatures begin to peak, thus mitigating the impact of the peak temperatures on the ecosystem (Schlenker and Roberts, 2009).

These results provide an insight into the changes that are occurring to the regional climate system within the GP. While the synoptic patterns for precipitation and temperature over the region are better 
understood, the influences of other critical features that drive climatological processes such as land-atmosphere interactions are less so, especially for precipitation (André et al., 1990; Pielke et al., 1991; Koster et al., 2004; Haugland and Crawford, 2005; Alfieri et al., 2008). Future work is likely to be directed into two different areas: first investigating the ADI in terms of reanalysis and model output and second investigating the connection between plant vigour and health [vegetation indices (e.g. NDVI, EVI), net primary productivity (NPP) or gross primary productivity (GPP)] of terrestrial ecosystems (Zhang et al., 2016). Analysis of model and reanalysis output of ADI values and trends will allow for further quantification of the causes of ADI variability and the changes this feature could incur in the future. Furthermore, the analysis of modelled ADI across the GP would allow for features seen in the observational data set identified within this study to be investigated in more detail, specifically the differences observed between positive and negative ADI regimes and the causes of the increased variability of ADI. Additionally, while the link between this feature of the GP climate and the ecosystem is intuitive and supported by literature, quantifying it using vegetation indices or vegetation health statistics could provide insights into the direct effect the shifts in the ADI detailed by this study are having on the ecosystem.

Whether the noted shifts in the ADI are being caused by human influences or natural variability cannot be determined within the scope of this study. However, the duration of these trends along with the specific signals noted after 1950 in the variability of ADI yield evidence that a change has occurred within the natural variability likely impacted by anthropogenic influences. Furthermore, the results are consistent with Christian et al. (2015) and Weaver et al. (2016), which both demonstrated increased variability of precipitation in the GP domain.

Acknowledgments - The authors would like to thank Dr Michael Richman for his insights regarding this study. I would also like to thank the anonymous reviewers for their comments in refining this work. This work was supported, in part, by the Agriculture and Food Research Initiative Competitive Grant (2012-02355) from the USDA National Institute of Food and Agriculture. Support for the NOAA-CIRES Twentieth Century Reanalysis Project version $2 c$ data set is provided by the U.S. Department of Energy, Office of Science Biological and Environmental Research (BER), and by the National Oceanic and Atmospheric Administration Climate Program Office. 


\section{References}

Alfieri L, Claps P, D’Odorico P, Laio F, Over T. 2008. An analysis of the soil moisture feedback on convective and stratiform precipitation. $J$. Hydrometeorol. 9: 280-291, doi: 10.1175/2007JHM863.1.

André JC, Bougeault P, Goutorbe JP. 1990. Regional estimates of heat and evaporation fluxes over nonhomogeneous terrain: examples from the HAPEXMOBILHY Programme. Bound.-Layer Meteorol. 50: 77-108, doi: 10.1007/BFo0120519.

Badeck FW, Bondeau A, Böttcher K, Doktor D, Lucht W, Schaber J, Sitch S. 2004. Responses of spring phenology to climate change. New Phytol. 162: 295-309, doi: 10.1111/j.1469-8137.2004.01059.x.

Bartz JA, Brecht JK. 2002. Postharvest Physiology and Pathology of Vegetables, 2nd edn. CRC Press: Boca Raton, FL, 744 pp.

Berg A, Lintner BR, Findell KL, Malyshev S, Loikith PC, Gentine P. 2014. Impact of soil moisture-atmosphere interactions on surface temperature distribution. $J$. Clim. 27: 7976-7993, doi: 10.1175/ JCLI-D-13-00591.1.

Berg A, Lintnera BR, Findellc K, Seneviratned SI, van den Hurke B, Ducharnef A, Chéruyg F, Hagemannh S, Lawrencei DM, Malyshevj S, Meierk A, Gentinel P. 2015. Interannual coupling between summertime surface temperature and precipitation over land: processes and implications for climate change. J. Clim. 28: 1308-1328, doi: 10.1175/JCLI-D-14-00324.1.

Bertin RI. 2008. Plant phenology and distribution in relation to recent climate change. J. Torrey Bot. Soc. 135: 126-146, doi: 10.3159/o7-RP-035R.1.

Bluestein HB. 1993. Synoptic-Dynamic Meteorology in Midlatitudes. Oxford University Press: New York, NY.

Blum A. 2010. Plant Breeding for Water-Limited Environments, 11th edn. Springer Science+Business Media: New York, NY.

Bukovsky MS, Karoly DJ. 2011. A regional modeling study of climate change impacts on warm-season precipitation in the central United States. J. Clim. 24: 1985-2002, doi: 10.1175/ 2010JCLI3447.1.

Caesar J, Alexander L, Vose RS. 2006. Large-scale changes in observed daily maximum and minimum temperatures: creation and analysis of a new gridded data set. J. Geophys. Res. 111: Do5101, doi: 10.1029/2005JDoo6280.

Christian J, Christian K, Basara JB. 2015. Drought and pluvial dipole events within the great plains of the United States. J. Appl. Meteorol. Climatol. 54: 18861898, doi: 10.1175/JAMC-D-15-0002.1.

Cleland EE, Chuine I, Menzel A, Mooney HA, Schwartz MD. 2007. Shifting plant phenology in response to global change. Trends Ecol. Evol. 22: 357-365, doi: 10.1016/j.tree.2007.04.003.

Compo GP, Whitaker JS, Sardeshmukh PD, Matsui N, Allan RJ, Yin X, Gleason Jr BE, Vose RS, Rutledge G, Bessemoulin P, Brönnimann S, Brunet M, Crouthamel RI, Grant AN, Groisman PY, Jones PD, Kruk MC, Kruger AC, Marshall GJ, Maugeri M, Mok HY, Nordli Ø, Ross TF, Trigo RM, Wang XL, Woodruff SD, Worley SJ. 2011. The twentieth century reanalysis project. Q. J. R. Meteorol. Soc. 137: 1-28, doi: 10.1002/qj.776. 
Di L, Rundquist DC, Han L. 1994. Modelling relationships between NDVI and precipitation during vegetative growth cycles. Int. J. Remote Sens. 15: 2121-2136.

Durre I, Wallace JM, Lettenmaier DP. 2000. Dependence of extreme daily maximum temperatures on antecedent soil moisture in the contiguous United States during summer. J. Clim. 13: 2641-2651, doi: 10.1175/1520-0442(2000)013<2641:DOEDMT>2.0.CO;2.

EasterlingDR, Robinson PJ. 1985. The diurnal variation of thunderstorm activity in the United States. J. Clim. Appl. Meteorol. 24: 1048-1058, doi: 10.1175/1520-0450(1985)024<1048:TDVOTA>2.0.CO;2.

Fay PA. 2009. Precipitation variability and primary productivity in water-limited ecosystems: how plants 'leverage' precipitation to 'finance' growth. New Phytol. 181: 5-8, doi: 10.1111/j.1469-8137. 2008.02695.x.

Fischer ML, Billesbach DP, Berry JA, Riley WJ, Torn MS. 2007. Spatiotemporal variations in growing season exchanges of $\mathrm{CO}_{2}, \mathrm{H}_{2} \mathrm{O}$, and sensible heat in agricultural fields of the Southern Great Plains. Earth Interact. 11: 1-21, doi: 10.1175/EI231.1.

Groisman PY, Knight RW, Karl TR. 2012. Changes in intense precipitation over the central United States. J. Hydrometeorol. 13: 47-66, doi: 10.1175/ JHM-D-11-039.1.

Haugland MJ, Crawford KC. 2005. The diurnal cycle of land- atmosphere interactions across Oklahoma's winter wheat belt. Mon. Weather Rev. 133: 120130, doi: 10.1175/MWR-2842.1.

Hughes L. 200o. Biological consequences of global warming: is the signal already apparent? Trends Ecol. Evol. 15: 56-61, doi: 10.1016/ So169-5347(99)01764-4.

Illston BG, Basara JB, Crawford KC. 2004. Seasonal to interannual variations of soil moisture measured in Oklahoma. Int. J. Climatol. 24: 1883-1896, doi: 10.1002/joc.1077.

Jamieson MA, Trowbridge AM, Raffa KF, Lindroth RL. 2012. Consequences of climate warming and altered precipitation patterns for plant-insect and multitrophic interactions. Plant Physiol. 16o: 1719-1727, doi: 10.1104/pp. 112.206524.

Jongen M, Pereira JS, Aires LMI, Pio CA. 2011. The effects of drought and timing of precipitation on the inter-annual variation in ecosystem-atmosphere exchange in a Mediterranean grassland. Agric. For. Meteorol. 151(5): 595-6o6.

Karl TR, Williams CN Jr. 1987. An approach to adjusting climatological time series for discontinuous inhomogeneities. J. Clim. Appl. Meteorol. 26: 1744-1763, doi: 10.1175/1520-0450(1987) 026<1744:AATACT>2.0.CO;2.

Karl TR, Williams CN Jr, Young PJ, Wendland WM. 1986. A model to estimate the time of observation bias associated with monthly mean maximum, minimum, and mean temperature for the United States. J. Clim. Appl. Meteorol. 25: 14516o, doi: 10.1175/1520-0450(1986)025<0145:AMTETT>2.0.CO;2.

Karl TR, Diaz HF, Kukla G. 1988. Urbanization: its detection and effect in the United States climate record. J. Clim. 1: 1099-1123, doi: 10.1175/1520-0442(1988)oo1<1099:UIDAEI>2.0.CO;2. 
Koster RD, Dirmeyer PA, Guo Z, Bonan G, Chan E, Cox P, Gordon CT, Kanae S, Kowalczyk E, Lawrence D, Liu P, Lu C-H, Malyshev S, McAvaney B, Mitchell K, Mocko D, Oki T, Oleson K, Pitman A, Sud YC, Taylor CM, Verseghy D, Vasic R, Xue Y, Yamada T. 2004. Regions of strong coupling between soil moisture and precipitation. Science 305: 1138-1140, doi: 10.1126/science.1100217.

Kumar S, Kinter J III, Dirmeyer PA, Pan Z, Adams J. 2013. Multidecadal climate variability and the "warming hole" in North America: results from CMIP5 twentieth- and twenty-first-century climate simulations. J. Clim. 26: 35113527, doi: 10.1175/JCLI-D-12-00535.1.

Kunkel KE, Liang XZ, Zhu JH. 2010. Regional climate model projections and uncertainties of U.S. summer heat waves. J. Clim. 23: 4447-4458, doi: 10.1175/2010JCLI3349.1.

Linderholm HW. 2006. Growing season changes in the last century. Agric. For. Meteorol. 137: 1-14, doi: 10.1016/j.agrformet. 2006.03.006.

Lobell DB, Asner GP. 2003. Climate and management contributions to recent trends in agricultural yields. Science 299: 1032, doi: 10.1126/science.1078475.

Long D, Scanlon BR, Fernando DN, Meng L, Quiring SM. 2012. Are temperature and precipitation extremes increasing over the U.S. high plains? Earth Interact 16: 1-20, doi: 10.1175/2012EIooo454.1.

Martyniak L. 2008. Response of spring cereals to a deficit of atmospheric precipitation in the particular stages of plant growth. Agric. Water Manage. 95: 171-178, doi: 10.1016/j.agwat.2007.10.014.

Méndez-Barroso LA, Vivoni ER, Watts CJ, Rodríguez JC. 2009. Seasonal and interannual relations between precipitation, surface soil moisture and vegetation dynamics in the North American monsoon region. J. Hydrol. 377: 59-70, doi: 10.1016/j.jhydrol.2009.08.009.

Menne MJ, Durre I, Gleason BG, Houston TG, Vose RS. 2012. An overview of the Global Historical Climatology Network-Daily database. J. Atmos. Oceanic Technol. 29: 897-910, doi: 10.1175/ JTECH-D-11-00103.1.

Menzel A. 2003. Plant phenological anomalies in Germany and their relation to air temperature and NAO. Clim. Change 57: 243-263, doi: 10.1023/A:1022880418362.

Menzel A, Sparks TH, Estrella N, Koch E, Aasa A, Ahas R, Al-Kübler K, Bissolli P, Braslavská O, Briede A, Chmielewski FM, Crepinsek Z, Curnel Y, Dahl Å, Defila C, Donnelly A, Filella Y, Jatczak K, Måge F, Mestre A, Nordli Ø, Peñuelas J, Pirinen P, Remišová V, Scheifinger H, Striz M, Susnik A, Van Vliet AJH, Wielgolaski F-E, Zach S, Zust A. 2006. European phenological response to climate change matches the warming pattern. Glob. Change Biol. 12: 19691976, doi: 10.1111/j.1365-2486.2006.01193.x.

Olesen JE, Bindi M. 2002. Consequences of climate change for European agricultural productivity, land use and policy. Eur. J. Agron. 16: 239-262, doi: 10.1016/S1161-0301(02)00004-7.

Pielke RA, Dalu GA, Snook JS, Lee TJ, Kittel TGF. 1991. Nonlinear influence of mesoscale land use on weather and climate. J. Clim. 4: 1053-1069, doi: 10.1175/1520-0442(1991)004< 1053:NIOMLU>2.0.CO;2. 
Quayle RG, Easterling DR, Karl TR, Hughes PY. 1991. Effects of recent thermometer changes in the cooperative station network. Bull. Am. Meteorol. Soc. 72: 1718-1723, doi: 10.1175/1520-0477(1991) 072<1718:EORTCI>2.0.CO;2.

Rasmusson EM. 1971. Diurnal variation of thunderstorm activity over the U.S. Tech. Note 71-4, U.S. Air Force Environmental Technical Applications Center, Washington, DC, $12 \mathrm{pp}$.

Regonda S, Rajagopalan B, Clark M, Pitlick J. 2005. Seasonal cycle shifts in hydroclimatology over the western United States. J. Clim. 18: 372-384, doi: 10.1175/JCLI-3272.1.

Ropelewski C, Halpert M. 1986. North American precipitation and temperature patterns associated with the El Niño/Southern Oscillation (ENSO). Mon. Weather Rev. 114: 2352-2362, doi: 10.1175/15200493 (1986)114,2352:NAPATP.2 .o.CO;2.

Rosenzweig C. 1990. Crop response to climate change in the southern Great Plains: a simulation study. Prof. Geogr. 1: 20-37, doi: 10.1111/j.0033-0124.1990.00020.x.

Ruiz-Barradas A, Nigam S. 2010. Great Plains precipitation and its SST links in twentieth-century climate simulations, and twenty-first- and twenty-second-century climate projections. J. Clim. 23: 6409-6429, doi: 10.1175/2010JCLI3173.1.

Schlenker W, Roberts MJ. 2009. Nonlinear temperature effects indicate severe damages to U.S. crop yields under climate change. Proc. Natl. Acad. Sci. USA 106: 15594-15598, doi: 10.1073/pnas.0906865106.

Schwartz MD, Ahas R, Aasa A. 2006. Onset of spring starting earlier across the Northern Hemisphere. Glob. Change Biol. 12: 343-351, doi: 10.1111/j.1365-2486.2005.01097.x.

Seneviratne SI, Corti T, Davin EL, Hirschi M, Jaeger EB, Lehner I, Orlowsky $\mathrm{B}$, Teuling AJ. 2010. Investigating soil moisture climate interactions in a changing climate: a review. Earth Sci. Rev. 99: 125-161, doi: 10.1016/j. earscirev.2010.02.004.

Shi X, Durran D. 2016. Sensitivities of extreme precipitation to global warming are lower over mountains than over oceans and plains. J. Clim. 29: 4779-4791, doi: 10.1175/JCLI-D-15-0576.1.

Stewart IT, Cayan DR, Dettinger MD. 2004. Changes in snowmelt runoff timing in western North America under a "business as usual" climate change scenario. Clim. Change 62: 217-232, doi: 10.1023/B:CLIM.ooooo13702.22656.e8.

Terjung WH, Liverman DM, Hayes JT. 1984. Climatic change and water requirements for grain corn in the North American Great Plains. Clim. Change 6: 193-220, doi: 10.1007/BFoo144612.

Teuling AJ, Troch PA. 2005. Improved understanding of soil moisture variability dynamics. Geophys. Res. Lett. 32: L05404, doi: 10.1029/2004GL021935.

Tubiello FN, Rosenzweig C, Goldberg RA, Jagtap S, Jones JW. 2002. Effects of climate change on US crop production: simulation results using two different GCM scenarios. Part I: wheat, potato, maize, and citrus. Clim. Res. 20: 259270, doi: 10.3354/cro20259. 
Tubiello FN, Soussana J-F, Howden SM. 2007. Crop and pasture response to climate change. Proc. Natl. Acad. Sci. USA 104: 19686-1969o, doi: 10.1073/ pnas.0701728104.

Turner NC, Begg JE. 1981. Plant-water relations and adaptation to stress. Plant Soil 58: 97-131, doi: 10.1007/BF02180051.

Vivoni ER, Moreno HA, Mascaro G, Rodriguez JC, Watts CJ, Garatuza-Payan J, Scott RL. 2008. Observed relation between evapotranspiration and soil moisture in the North American monsoon region. Geophys. Res. Lett. 3: L22403, doi: 10·1029/2008GL036001.

Wallace JM. 1975. Diurnal variations in precipitation and thunderstorm frequency over the coterminous United States. Mon. Weather Rev. 103: 406-419, doi: 10.1175/1520-0493(1975)103<0406:DVIPAT>2.0.CO;2.

Weaver S, Baxter S, Harnos K. 2016. Regional changes in the interannual variability of warm season precipitation. J. Clim. 29: 5157-5173, doi: 10.1175/ JCLI-D-14-00803.1.

Weltzin JF, McPherson GR. 2003. Predicting the response of terrestrial ecosystems to potential changes in precipitation regimes. In Changing Precipitation Regimes and Terrestrial Ecosystems: A North American Perspective. University of Arizona Press: Tucson, AZ, 3-8.

Zeppel MJB, Wilks JV, Lewis JD. 2014. Impacts of extreme precipitation and seasonal changes in precipitation on plants. Biogeosciences 11(3083-3093): 2014, doi: 10.5194/bg-11-3083-2014.

Zhang Y, Xiao X, Jin C, Dong J, Zhou S, Wagle P, Joiner J, Guanter L, Zhang Y, Zhang G, Qin Y, Wang J, Moore BI. 2016. Consistency between sun-induced chlorophyll fluorescence and gross primary production of vegetation in North America. Remote Sens. Environ. 183: 154-169, doi: 10.1016/j.rse.2016.05.015. 